\title{
Evolutionary Diversification of Mesobuthus $\alpha$-Scorpion Toxins Affecting Sodium Channels ${ }^{\boldsymbol{*}_{\text {[S }}}$
}

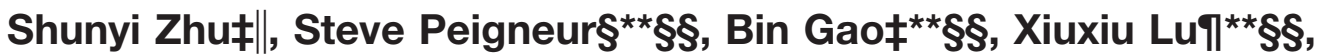 \\ Chunyang Caoๆ||, and Jan Tytgat§\|
}

$\alpha$-Scorpion toxins constitute a family of peptide modulators that induce a prolongation of the action potential of excitable cells by inhibiting voltage-gated sodium channel inactivation. Although they all adopt a conserved structural scaffold, the potency and phylogentic preference of these toxins largely vary, which render them an intriguing model for studying evolutionary diversification among family members. Here, we report molecular characterization of a new multigene family of $\alpha$-toxins comprising 13 members (named MeuNaTx $\alpha-1$ to MeuNaTx $\alpha-13$ ) from the scorpion Mesobuthus eupeus. Of them, five native toxins (MeuNaTx $\alpha-1$ to -5 ) were purified to homogeneity from the venom and the solution structure of MeuNaTx $\alpha-5$ was solved by nuclear magnetic resonance. A systematic functional evaluation of MeuNaTx $\alpha-1,-2,-4$, and -5 was conducted by two-electrode voltage-clamp recordings on seven cloned mammalian voltage-gated sodium channels $\left(\mathrm{Na}_{\mathrm{v}} \mathrm{1.2}\right.$ to $\left.\mathrm{Na}_{\mathrm{v}} 1.8\right)$ and the insect counterpart $\mathrm{DmNa}_{\mathrm{v}} 1$ expressed in Xenopus oocytes. Results show that all these four peptides slow inactivation of $\mathrm{DmNa}_{\mathrm{v}} 1$ and are inactive on $\mathrm{Na}_{\mathrm{v}} 1.8$ at micromolar concentrations. However, they exhibit differential specificity for the other six channel isoforms $\left(\mathrm{Na}_{\mathrm{v}} 1.2\right.$ to $\left.\mathrm{Na}_{\mathrm{v}} 1.7\right)$, in which MeuNaTx $\alpha-4$ shows no activity on these isoforms and thus represents the first Mesobuthus-derived insect-selective $\alpha$-toxin identified so far with a half maximal effective concentration of $130 \pm 2 \mathrm{~nm}$ on $\mathrm{DmNa}_{\mathrm{v}} 1$ and a half maximal lethal dose of about $200 \mathrm{pmol} \mathrm{g}^{-1}$ on the insect Musca domestica; MeuNaTx $\alpha-2$ only affects $\mathrm{Na}_{v} 1.4$; MeuNaTx $\alpha-1$ and MeuNaTx $\alpha-5$ have a wider range of channel spectrum, the former active on $\mathrm{Na}_{\mathrm{v}} 1.2, \mathrm{Na}_{\mathrm{v}} 1.3$, $\mathrm{Na}_{\mathrm{v}}$ 1.6, and $\mathrm{Na}_{\mathrm{v}}$ 1.7, whereas the latter acting on $\mathrm{Na}_{\mathrm{v}}$ 1.3$\mathrm{Na}_{\mathrm{v}}$ 1.7. Remarkably, MeuNaTx $\alpha-4$ and MeuNaTx $\alpha-5$ are two nearly identical peptides differing by only one point mutation at site 50 (A50V) but exhibit rather different channel subtype selectivity, highlighting a switch role of

From the ¥Group of Animal Innate Immunity, State Key Laboratory of Integrated Management of Pest Insects and Rodents, Institute of Zoology, Chinese Academy of Sciences, 1 Beichen West Road, Chaoyang District, Beijing 100101, China; §Laboratory of Toxicology, University of Leuven, O\&N 2, Herestraat 49, P.O. Box 922, 3000 Leuven, Belgium; ๆState Key Laboratory of Bio-organic and Natural Product Chemistry Shanghai Institute of Organic Chemistry, Chinese Academy of Sciences, 345 Lingling Road, Shanghai 200032, China

Received June 16, 2011, and in revised form, September 1, 2011

Published, MCP Papers in Press, October 3, 2011, DOI 10.1074/ mcp.M111.012054 this site in altering the target specificity. By the maximum likelihood models of codon substitution, we detected nine positively selected sites (PSSs) that could be involved in functional diversification of Mesobuthus $\alpha$-toxins. The PSSs include site 50 and other seven sites located in functional surfaces of $\alpha$-toxins. This work represents the first thorough investigation of evolutionary diversification of $\alpha$-toxins derived from a specific scorpion lineage from the perspectives of sequence, structure, function, and evolution. Molecular \& Cellular Proteomics 11: 10.1074/ mcp.M111.012054, 1-18, 2012.

Venomous animals, such as sea anemones, scorpions, spiders, cone snails, jellyfish, and snakes, represent a distinct group of organisms that evolve toxins to help them capture prey and defend themselves from predators (1). These animals occupy diverse ecological niches and have different evolutionary histories and food sources, but they convergently select voltage-gated sodium channels (VGSCs) ${ }^{1}$ as molecular targets for their toxins that can strongly modify VGSCs' functions to alter electrical excitability of an animal's neuromuscular system and thus cause rapid immobilization of both prey and competitors $(2,3)$. VGSCs play vital roles in the normal functioning of excitable tissues (neurons, muscles, and heart). These large, complex membrane proteins are composed of one principal $\alpha$-subunit of $220-260 \mathrm{kDa}$ associated with one or more auxiliary $\beta$-subunits of $\sim 33-36 \mathrm{kDa}$ in some tissues of mammals and the tipE subunit in insects (4-6). The $\alpha$-subunit of VGSCs includes four homologous domains (DI-DIV) connected by intracellular and extracellular loops, each domain containing six helical transmembrane segments (S1-S6), and a hairpin-like P loop between S5 and S6 that forms the ion selectivity filter. Thus far, at least seven distinct receptor sites have been identified on the $\alpha$-subunits for various animal-derived toxins that either affects ion permeation or voltage-dependent gating properties (7), of which

${ }^{1}$ The abbreviations used are: VGSC, voltage-gated sodium channel; 3'-UTR, 3'-untranslational region; $\mathrm{CS} \alpha \beta$, cysteine-stabilized $\alpha$-helical and $\beta$-sheet; MALDI-TOF MS, matrix-assisted laser desorption ionization time-of-flight mass spectrometry; MeuNaTx $\alpha, \mathrm{Me}-$ sobuthus eupeus $\alpha$-scorpion toxin; PSS, positively selected site; RACE, rapid amplification of CDNA end; RP-HPLC, reversed-phase high-performance liquid chromatography; TTX, tetrodotoxin. 


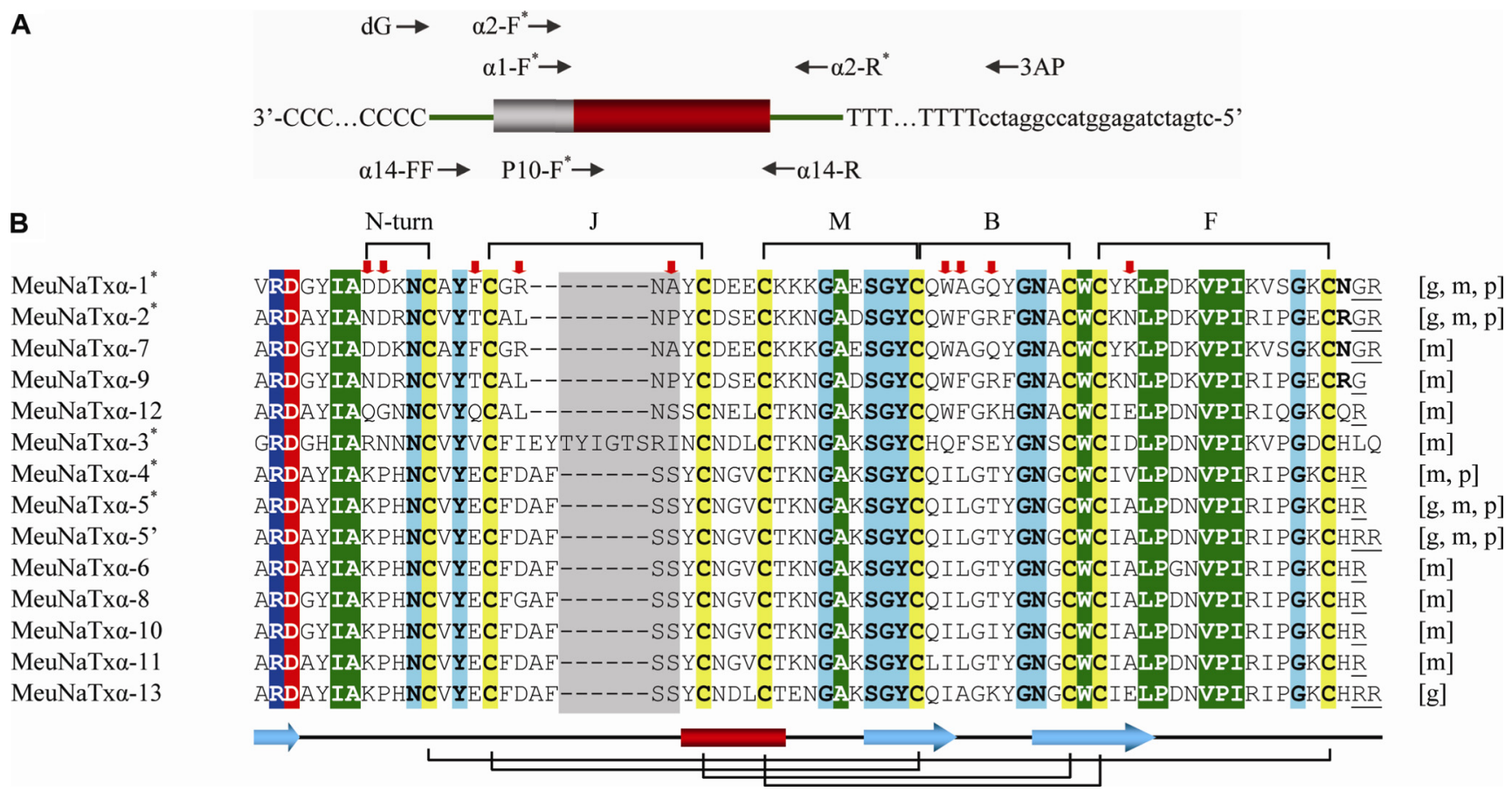

FIG. 1. The multigene family of $\alpha$-toxins in M. eupeus. A, Strategy for isolating cDNAs of a complete $\alpha$-toxin multigene family in $M$. eupeus by combination of different primers (represented by arrows) whose sequence information and pairs for PCR amplification are provided in supplemental Table S1 and S2. Different regions of the tailed first-strand cDNA encoding an $\alpha$-toxin are shown in color. UTR, untranslational region. SP, signal peptide. MP, mature peptide; $B$, Multiple sequence alignment of $\alpha$-toxins. Cysteines are shadowed in yellow and residues conserved across the alignment in color (Basic: blue; hydrophobic: green; polar: cyan). Extra C-terminal amino acids are underlined once and amidated residues are boldfaced. Secondary structure elements (arrow: $\beta$-strand; cylinder: $\alpha$-helix) and four disulfide bridges (indicated by lines) extracted from the NMR structure of MeuNaTx $\alpha-5$ are shown at the bottom of the alignment. PSSs predicted from the codon-substitution model are indicated by red arrows. $\mathrm{N}$-turn and four loops $(\mathrm{J}, \mathrm{M}, \mathrm{B}$, and $\mathrm{F}$ ) are shown at the top of the alignment. $\mathrm{g}, \mathrm{m}$, and $\mathrm{p}$ represent genomic, mRNA and protein, respectively. ${ }^{*}$ indicates $\operatorname{MeuNaTx} \alpha$, where native peptides were isolated from the venom.

receptor sites 3,4 , and 6 are targeted by several types of water-soluble polypeptide toxins from scorpions, spiders, sea anemone, and cone snails, whereas site 1 is shared by the peptide toxin $\mu$-conotoxin from cone snails and tetrodotoxin (TTX), a heterocyclic guanidine alkaloid harbored naturally by bacteria and animals of phylogenetically diverse origins (e.g. fish, octopus, and newt) $(8,9)$.

It is known that Drosophila has a single VGSC $\alpha$-subunit $\left(\mathrm{DmNa}_{v} 1\right)$ encoded by para whereas mammals have at least nine $\alpha$-subunit isoforms $\left(\mathrm{Na}_{\mathrm{v}} 1.1-\mathrm{Na}_{\mathrm{v}} 1.9\right)$ that constitute a single gene family of proteins with more than $70 \%$ amino acid sequence identity in their transmembrane segments (4-6). Members in the VGSC family have different tissue distributions and developmental expression patterns (10). For example, $\mathrm{Na}_{\mathrm{v}} 1.2$ and $\mathrm{Na}_{\mathrm{v}} 1.3$ are mainly expressed in central nervous system whereas $\mathrm{Na}_{v} 1.7, \mathrm{Na}_{v} 1.8$, and $\mathrm{Na}_{v} 1.9$ are specific to peripheral nervous system. $\mathrm{Na}_{\mathrm{v}} 1.1$ and $\mathrm{Na}_{\mathrm{v}} 1.6$ expression is common to central nervous system and peripheral nervous system. $\mathrm{Na}_{\mathrm{v}} 1.4$ is expressed in skeletal muscles whereas $\mathrm{Na}_{\mathrm{v}} 1.5$ is the main isoform in cardiac muscle. Based on sensitivity to TTX, these channels are distinguished into TTXsensitive (TTX-S) and TTX-resistant (TTX-R) subtypes (11). The former includes $\mathrm{Na}_{v} 1.1, \mathrm{Na}_{v} 1.2, \mathrm{Na}_{\mathrm{v}} 1.3, \mathrm{Na}_{\mathrm{v}} 1.4, \mathrm{Na}_{\mathrm{v}} 1.6$, and $\mathrm{Na}_{v} 1.7$ and the latter consists of $\mathrm{Na}_{v} 1.5, \mathrm{Na}_{v} 1.8$, and
$\mathrm{Na}_{v}$ 1.9. The recognition of these channel subtypes and elucidation of their structure, pharmacological function, and biological role is technically difficult because it requires highly selective molecular probes.

Scorpion toxins specific for VGSCs (NaScTxs) are essential components identified with their functions associated to venom toxicity $(12,13)$. These molecules comprise a family of evolutionarily conserved gating modulators that are composed of 61-76 residues and are cross-linked by four disulfide bridges (14). NaScTxs belong to the superfamily of cysteinestabilized $\alpha$-helical and $\beta$-sheet (CS $\alpha \beta)$ motif-containing proteins (15) and most of them adopt the same secondary structure topology $(\beta \alpha \beta \beta)$. NaScTxs have been divided into two principle pharmacological types based on their electrophysiological effects and binding characteristics $(16,17) . \alpha$-Toxins that were exclusively found in Old World scorpions slow the VGSC inactivation to induce prolongation of action potentials by binding to the channel receptor site 3 , a key binding regions shared by sea-anemone toxins and some spider toxins. It has been proposed that such binding inhibits the outward movement of the S4 segment of domain IV and thereby prevents conformational changes required for fast inactivation (14). $\beta$-Toxins that are mainly derived from New World scorpions enhance the activation of VGSCs by binding to receptor 


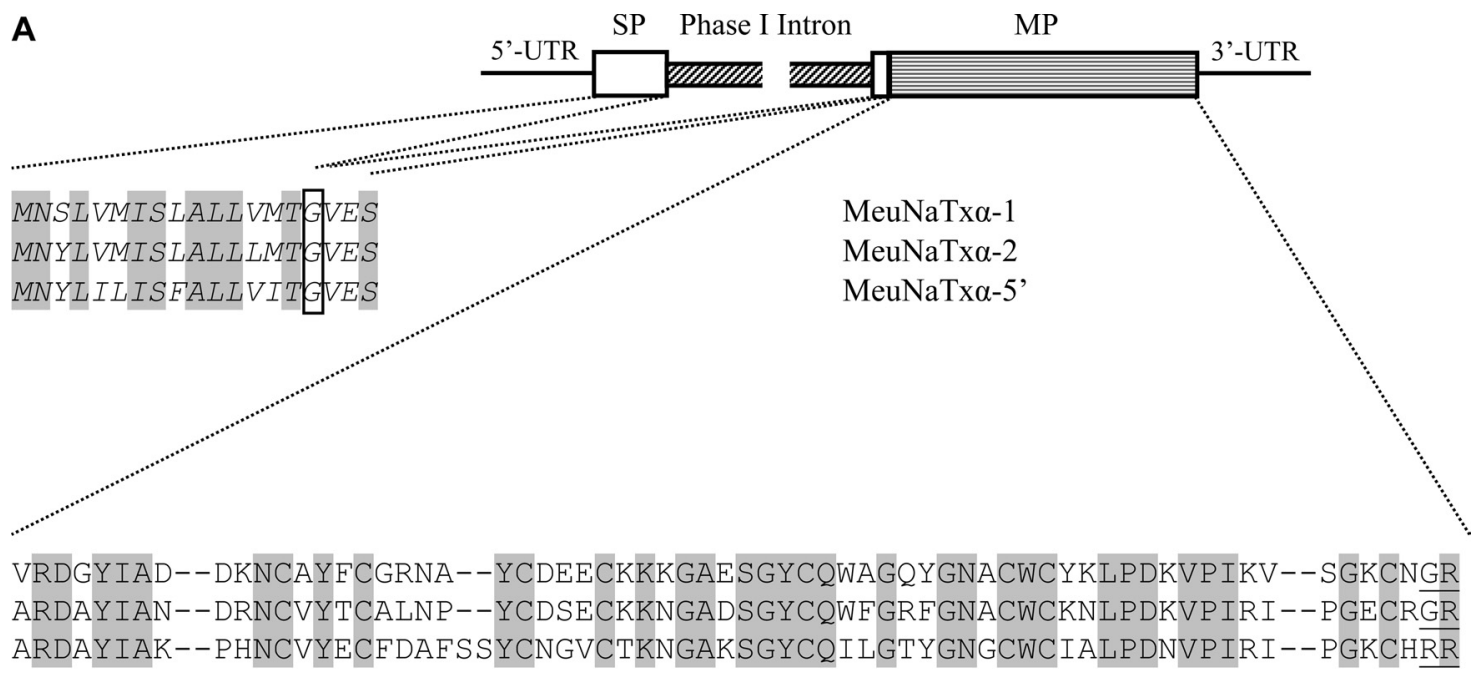

B

\begin{tabular}{|c|c|}
\hline MeuNaTx $\alpha-1$ & gtaagatttacatattcatagaataagt... [178 bp]...tatttttctgactacag \\
\hline MeuNaTx $\alpha-2$ & gtaagatttacatattcttagaataagt... [373 bp]...tttttttctgattacag \\
\hline MeuNaTx $\alpha-5$ & gtaagatttacatattcttaaaataagt...[363 bp].. \\
\hline
\end{tabular}

FIG. 2. Exon-intron structure of $\boldsymbol{M}$. eupeus $\boldsymbol{\alpha}$-toxins. $A$, Genomic organization conservation among MeuNaTx $\alpha-1$, MeuNaTx $\alpha-2$ and MeuNaTx $\alpha-5$. Signal peptide sequences are italicized and residues split by a phase I intron are boxed. Identical amino acids and nucleotides are shadowed in gray. Extra residues are underlined once; $B$, Conservation of 5'- and $3^{\prime}$-splicing sites of introns.

site 4 to shift the voltage dependence of activation to more negative membrane potentials. Despite similar functional properties, $\alpha$-toxins show remarkable differences in preference for insect and mammalian VGSCs and accordingly they can be further divided into three subtypes: (1) Classical $\alpha$-toxins that are highly selective on mammals and nontoxic to insects (e.g. AaHII and Lqh2); (2) Insect $\alpha$-toxins that are weakly toxic on mammals but especially toxic for insects (e.g. LqholT and Lqq3); and (3) $\alpha$-Like toxins that act on both mammalian and insect VGSCs (e.g. BmKM1 and Lqh3) (14, 18). Similarly, $\beta$-toxins also include several different pharmacological subtypes with various affinities toward insect or mammalian VGSCs (19), in which depressant and excitatory $\beta$-toxins primarily bind to insect sodium channels. The observed phylogenetic preference provides rationality for studying structure-function relationship of NaScTxs and for designing highly selective insecticidal peptides for pest control (20).

Here, we report a systematic investigation of a new multigene family of $\alpha$-toxins (named MeuNaTx $\alpha$ s) in Mesobuthus eupeus, a sibling species of the Chinese scorpion Mesobuthus martensii (21), through molecular cloning, biochemical purification, nuclear magnetic resonance analysis, functional characterization, and evolutionary study. We found that despite high sequence identity and overall structural similarity, each MeuNaTx $\alpha$ member has different selectivity on various VGSCs, which could be a consequence of positive selection for adaptation of channel alterations during an evolutionary arms race of Mesobuthus and its prey/competitor.

\section{MATERIALS AND METHODS}

Isolation of CDNA and Genomic Clones-Total RNA and genomic DNA of $M$. eupeus were isolated from the venom gland and legs, respectively, according to previously described methods (22). All the primers used here were synthesized by SBS Genetech (Beijing, China) (supplemental Table S1, provided as Electronic Supplementary Material). For $3^{\prime}$ rapid amplification of cDNA ends (3' RACE) of scorpion $\alpha$-toxins, total RNA was reverse-transcribed into the firststrand cDNAs using RT-PreMix Kit (SBS Genetech) and a universal oligo(dT)-containing adaptor primer (dT3AP). For 5' RACE, the firststrand cDNAs were tailed by terminal transferase and dCTP (Takara, Dalian, China). PCR amplification of cDNAs or genomic DNAs was carried out by TaKaRa LA Taq (Takara), a DNA polymerase with $3^{\prime} \rightarrow 5^{\prime}$ exonuclease proofreading activity, under standard PCR conditions. Primer pairs are provided in supplemental Table S2 and their locations indicated in Fig. 1A. All PCR products were ligated into pGM-T and resultant recombinant plasmids were transformed into Escherichia coli $\mathrm{DH} 5 \alpha$.

Recombinant clones were sequenced through the chain termination method using T7 primer. Nucleotide sequences for genes reported here have been deposited in the GenBank database (http:// www.ncbi.nlm.nih.gov/) under accession numbers provided in supplemental Table S3.

Biochemical Purification-Purification approaches used have been described previously (23). Briefly, $M$. eupeus crude venom collected by an electrical stimulation method was suspended in $0.1 \%$ trifluoroacetic acid (TFA, v/v) and directly subjected to reversed-phase high-performance liquid chromatography (RP-HPLC) isolation. All well-defined peaks were collected separately and rerun on the same column for further purification. The purity and molecular mass of MeuNaTx $\alpha$ s were determined by MALDI-TOF mass spectra on a Kratos PC Axima CFR plus (Shimadzu Co. LTD, Kyoto). The automated Edman degradation by ABI Procise 492cLC protein sequencer (Shanghai GeneCore BioTechnologies Co., Ltd., Shanghai, China) 


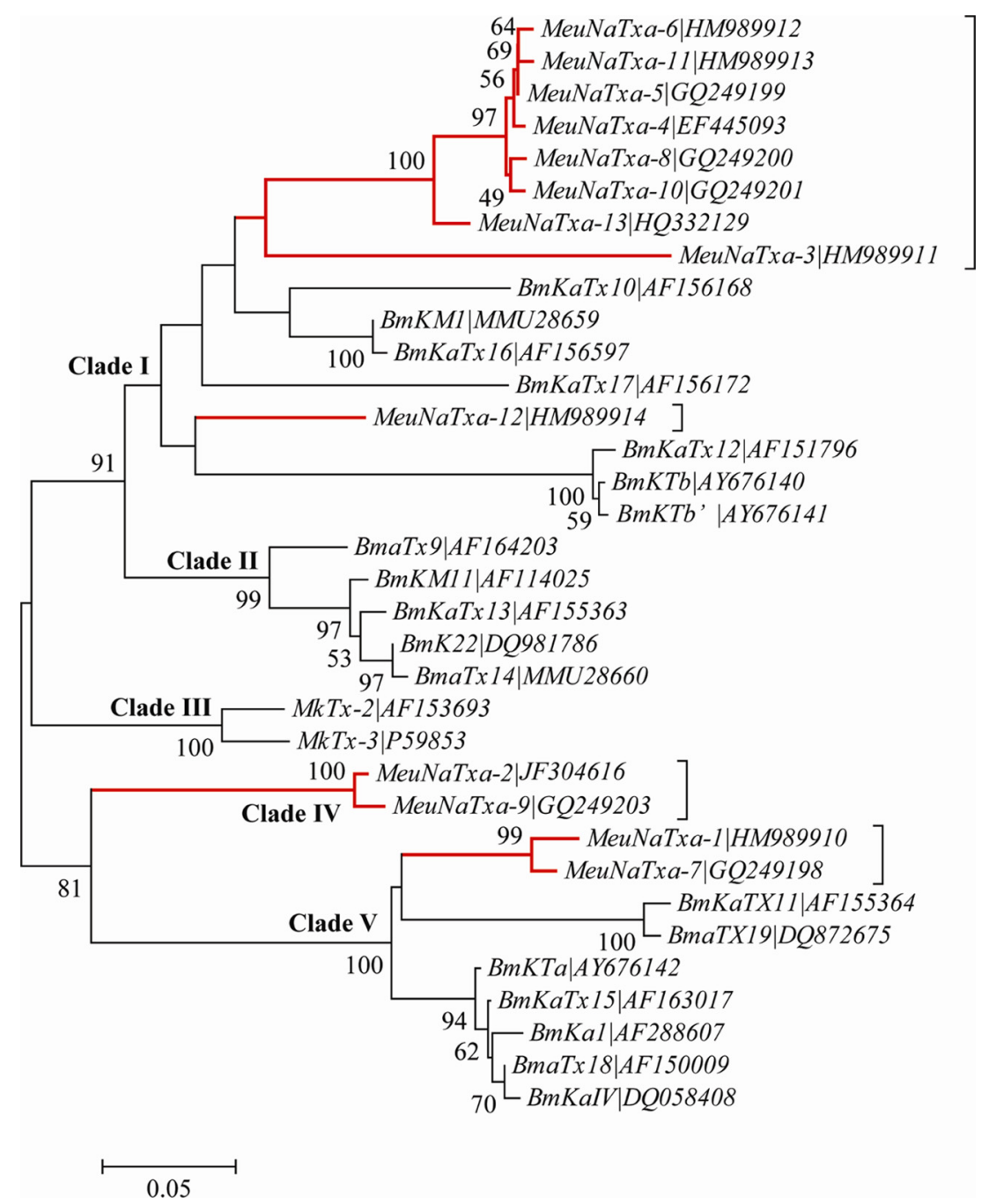

FIG. 3. Phylogenetic tree of Mesobuthus $\boldsymbol{\alpha}$-toxin genes. The tree is a bootstrap consensus tree based upon 1000 replicates of the Neighbor-Joining (NJ) algorithm with the Maximum Composite Likelihood model of DNA substitutions. The scale bar shows total nucleotide divergence. $>50 \%$ bootstrap values are shown at nodes. Branches derived from M. eupeus are in red. Similar tree topology was obtained with the Minimum Evolution (ME) or Unweighted Pair Group Method Algorithm (UPGMA) (data not shown).

were used to determine amino-terminal sequences of MeuNaTx $\alpha-1$, $-2,-4$ and -5 (Table I).

NMR Data Acquisition and Analysis-MeuNaTx $\alpha-5$ was dissolved at a concentration of $1 \mathrm{~mm}$ in $50 \mathrm{~mm} \mathrm{KH}_{2} \mathrm{PO}_{4}, \mathrm{pH} 4.0,10 \%(\mathrm{v} / \mathrm{v}) \mathrm{D}_{2} \mathrm{O}$. The sample was then freeze-dried and dissolved in $100 \% \mathrm{D}_{2} \mathrm{O}$ for measurements of amide protons exchange rate. NMR data were acquired at $298 \mathrm{~K}$ employing a Varian Inova spectrometer operating at $600 \mathrm{MHz}$ proton frequency. The TOCSY spectra were recorded with mixing times of 80 and $120 \mathrm{~ms}$, and the NOESY spectra were recorded with mixing times of $100,150,200$, and 250 ms. All twodimensional-NMR spectra were collected as $4096 \times 512$ data point matrices using 64-128 scans. NMR data were processed using vnmr or NMRPipe and a shifted sine window function and zero filling were applied prior to Fourier transformation. Data analysis was performed with Sparky 3 (http://www.cgl.ucsf.edu/home/sparky/).

Structure Calculation-Seven hundred and ten distance and 29 dihedral angle constraints were mainly derived from cross-peaks in NOESY (mix $=200 \mathrm{~ms}$ ). ${ }^{3} \mathrm{~J}_{\mathrm{HN}-\mathrm{Ha}}$ and ${ }^{3} \mathrm{~J}_{\mathrm{Ha}-\mathrm{Hb}}$ coupling constants obtained from DQF-COSY spectra were converted into dihedral angle constraints (24). Structures were generated using XPLOR-NIH (2.19 version), employing simulated annealing algorithms. Twenty-six hydrogen bond constraints were introduced based on the unexchanged backbone amide protons identified in DQF-COSY acquired in $\mathrm{D}_{2} \mathrm{O}$ and the assigned inerratic NOE pattern belonging to the $\alpha$-helix and $\beta$-sheet conformations. A total of 100 structures were calculated, and a final ensemble of 20 structures was selected without NOE violation $>0.3 \AA$, on the basis of the lowest XPLOR energies, to represent the final solution structure. Structure statistics for the 25 structures with the lowest energy were summarized in Table II. Structure evaluation was performed with the program PROCHECK-NMR. Threedimensional conformations were inspected in MOLMOL. The chemical shifts and coordinates of MeuNaTx $\alpha-5$ are deposited in the Biological Magnetic Resonce Bank (BMRB entry, 17988) and the Protein Data Bank (PDB entry, 2LKB), respectively.

Expression in Xenopus Oocytes-For the expression in Xenopus oocytes (25), the rNav1.2/pLCT1, rNav1.3/pLCT2, rNa $1.4 / p U I-2$, $\mathrm{mNa}_{\mathrm{v}} 1.6 / \mathrm{pLCT} 1$, and $\mathrm{hNa}_{\mathrm{v}} 1.8 / \mathrm{pBSTA}$ vectors were linearized with Notl. The $\mathrm{rNa}_{\mathrm{v}} 1.7 / \mathrm{pBSTA}$, and $\mathrm{h} \beta 1 / \mathrm{pGEM}-\mathrm{HE}$ vectors were linearized with Sacll and Nhel, respectively. These vectors were transcribed with the T7 mMESSAGE-mMACHINE transcription kit (Ambion, Aus- 


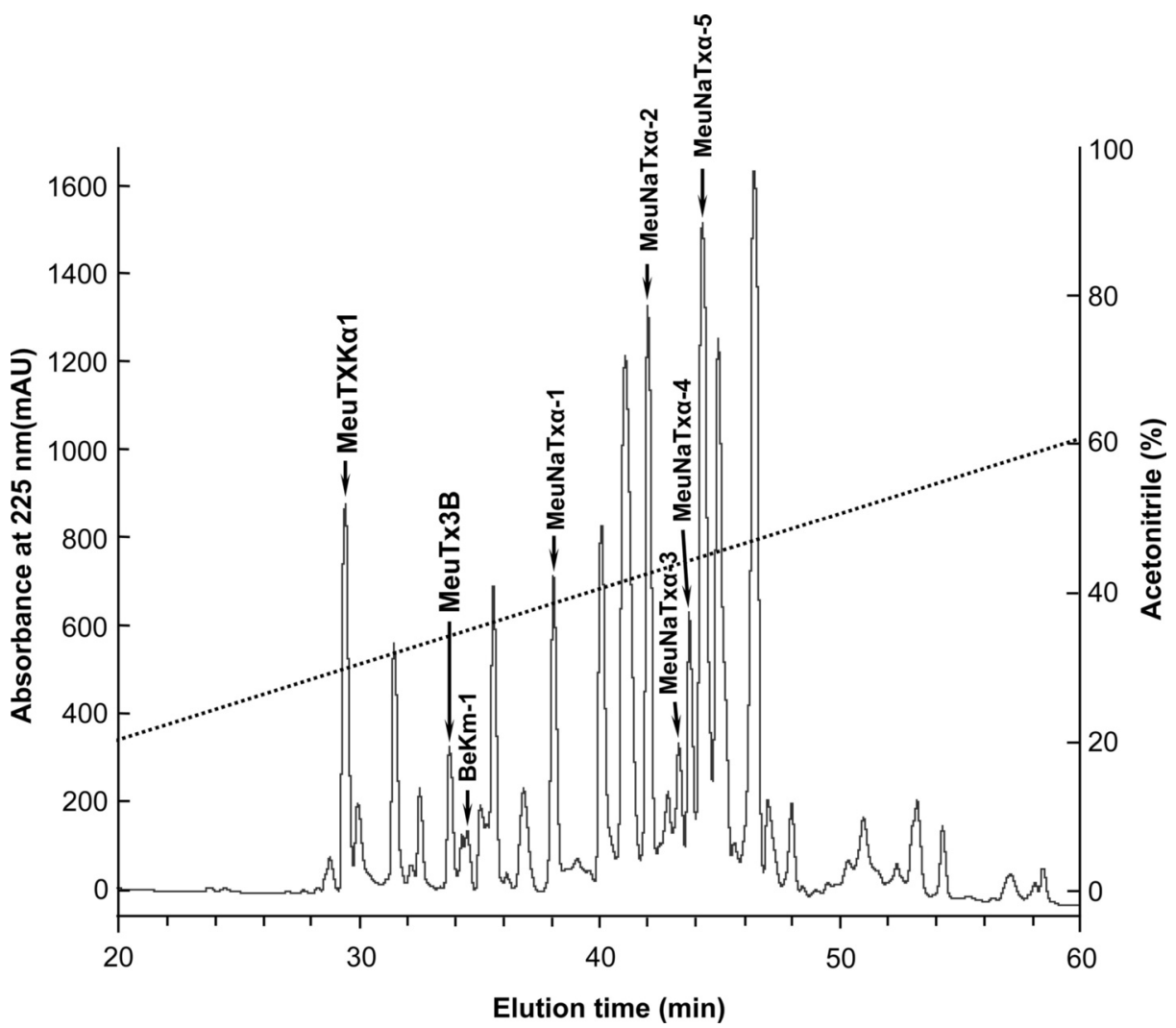

FIG. 4. Purification of scorpion $\alpha$-toxins from the $\boldsymbol{M}$. eupeus crude venom by RP-HPLC. Fractions corresponding to MeuNaTx $\alpha-1$ MeuNaTx $\alpha-5$ and those to three known peptides (MeuTXK $\alpha 1$, MeuTx3B and BeKm-1) (23) are indicated by arrows. The Agilent semi-prep Zorbax 300SB-C18 $(9.2 \times 250 \mathrm{~mm}, 5 \mu \mathrm{m})$ was equilibrated with $0.1 \%$ TFA in water $(\mathrm{v} / \mathrm{v})$ and peptide components were eluted from the column with a linear gradient from 0 to $60 \%$ acetonitrile in $0.1 \%$ TFA in water $(\mathrm{v} / \mathrm{v})$ within $60 \mathrm{~min}$ with a flow rate of $1 \mathrm{ml} / \mathrm{min}$. The UV absorbance trace was followed at $225 \mathrm{~nm}$.

TABLE I

Molecular and functional properties of Mesobuthus eupeus $\alpha$-toxins. - ${ }^{*}$, C-terminal amidation; $T_{R}$, retention time; ${ }^{\dagger}$, determined by MALDITOF; ", determined by Edman degradation; pl, theoretical isoelectric point; -, not determined

\begin{tabular}{|c|c|c|c|c|c|}
\hline & $\mathrm{T}_{R}(\min )$ & Theoretical MW (Da) & $\begin{array}{l}\text { Experimental } \\
\mathrm{MW}(\mathrm{Da})^{\dagger}\end{array}$ & $\mathrm{N}$-terminal sequence ${ }^{\pi}$ & pl \\
\hline MeuNaTx $\alpha-1^{*}$ & 38.2 & 7177.12 & 7178.27 & VRDGY & 8.14 \\
\hline $\operatorname{MeuNaTx} \alpha-2^{*}$ & 42.2 & 7233.19 & 7233.68 & ARDAYIANDR & 8.19 \\
\hline MeuNaTx $\alpha-4$ & 44.0 & 7199.27 & 7199.55 & ARDAYI & 8.19 \\
\hline MeuNaTx $\alpha-5 / 5$ & 44.4 & 7171.22 & 7170.47 & ARDAYIAKPHNCVYECFDAF & 8.19 \\
\hline MeuNaTx $\alpha-6$ & 43.5 & 7113.18 & - & - & 8.48 \\
\hline MeuNaTx $\alpha-9^{\star}$ & - & 7276.22 & - & - & 8.19 \\
\hline $\operatorname{MeuNaTx} \alpha-10$ & - & 7169.25 & - & - & 8.19 \\
\hline $\operatorname{MeuNaTx} \alpha-11$ & - & 7156.25 & - & - & 8.19 \\
\hline MeuNaTx $\alpha-12$ & - & 7050.00 & - & - & 8.20 \\
\hline MeuNaTx $\alpha-13$ & - & 7287.25 & - & - & 6.05 \\
\hline
\end{tabular}

tin, TX). The $h N a_{v} 1.5 / p S P 64 T$ and $r \beta 1 / p S P 64 T$ constructs were linearized with Xbal and EcoRI, respectively, and transcribed with the SP6 mMESSAGE-mMACHINE transcription kit (Ambion) (supplemental Table S4). The harvesting of stage V-VI oocytes from anesthetized female Xenopus laevis frog was as described previously. Oocytes were injected with $50 \mathrm{nl}$ of cRNA at a concentration of $1 \mathrm{ng} / \mathrm{nl}$ using a micro-injector (Drummond Scientific, Broomall, PA). The oocytes were incubated in a solution containing (in $\mathrm{mM}$ ): $\mathrm{NaCl}, 96$; $\mathrm{KCl}, 2 ; \mathrm{CaCl}_{2}, 1.8 ; \mathrm{MgCl}_{2}, 2$ and HEPES, 5 (pH 7.4), supplemented with $50 \mathrm{mg} / \mathrm{l}$ gentamycin sulfate and $180 \mathrm{mg} / \mathrm{l}$ theophylline.

Electrophysiological Recordings-Two-electrode voltage-clamp recordings were performed at room temperature $\left(18-22^{\circ} \mathrm{C}\right)$ using a Geneclamp 500 amplifier (Molecular Devices, Sunnyvale, CA) controlled by a pClamp data acquisition system (Axon Instruments, Union 
TABLE II

NMR structural statistics for MeuNaTx $\alpha-5$ calculation. r.m.s.d., rootmean-square deviation

NMR distance and dihedral constraints

\begin{tabular}{|c|c|}
\hline Intra-residue & 216 \\
\hline Sequential $(|i-j|=1)$ & 255 \\
\hline Medium range $(1<|i-j| \leq 5)$ & 122 \\
\hline Long range $(|i-j|>5)$ & 117 \\
\hline Hydrogen bonds & 26 \\
\hline Total NOE & 710 \\
\hline Dihedral angels & 29 \\
\hline \multicolumn{2}{|l|}{ r.m.s.d. versus the mean structure ( $(\AA)$} \\
\hline All backbone atoms & $1.50 \pm 0.20 \AA$ \\
\hline All heavy atoms & $2.11 \pm 0.20 \AA$ \\
\hline $\begin{array}{l}\text { Backbone atoms (2nd structural } \\
\text { region) }\end{array}$ & $0.52 \pm 0.15 \AA$ \\
\hline Heavy atoms (2nd structural region) & $0.92 \pm 0.20 \AA$ \\
\hline \multicolumn{2}{|l|}{ Structural statistics } \\
\hline \multicolumn{2}{|l|}{ r.m.s.d. versus the mean structure $(\AA ̊)$} \\
\hline NOE distances $(\AA)$ & $0.034 \pm 0.044$ \\
\hline Dihedral angles (deg.) & $0.49 \pm 0.079$ \\
\hline \multicolumn{2}{|l|}{ r.m.s.d. from idealized geometry } \\
\hline Bonds $(\AA)$ & $0.0016 \pm 0.00011$ \\
\hline Angles (deg.) & $0.30 \pm 0.014$ \\
\hline Impropers (deg.) & $0.26 \pm 0.013$ \\
\hline \multicolumn{2}{|l|}{ Structure Analysis } \\
\hline $\begin{array}{l}\% \text { of residues in most favored } \\
\text { regions }\end{array}$ & 77.2 \\
\hline $\begin{array}{l}\% \text { of residues in additionally allowed } \\
\text { regions }\end{array}$ & 16.9 \\
\hline $\begin{array}{l}\% \text { of residues in generously allowed } \\
\text { regions }\end{array}$ & 5.4 \\
\hline$\%$ of residues in disallowed regions & 0.6 \\
\hline
\end{tabular}

City, CA). Whole cell currents from oocytes were recorded 1-4 days after injection. Bath solution composition was (in $\mathrm{mm}$ ): $\mathrm{NaCl}, 96 ; \mathrm{KCl}, 2$; $\mathrm{CaCl}_{2}, 1.8 ; \mathrm{MgCl}_{2}, 2$; and HEPES, 5 (pH 7.4). Voltage and current electrodes were filled with $3 \mathrm{M} \mathrm{KCl}$. Resistances of both electrodes were kept at 0.8-1.8 M . The elicited currents were filtered at $1 \mathrm{kHz}$ and sampled at $20 \mathrm{kHz}$ using a four-pole low-pass Bessel filter. Leak subtraction was performed using a $-\mathrm{P} / 4$ protocol. In order to avoid overestimation of a potential toxin-induced shift in the current-voltage relationships of inadequate voltage control when measuring large sodium currents in oocytes, only data obtained from cells exhibiting currents with peak amplitude below $2 \mu \mathrm{A}$ were considered for analysis.

For the electrophysiological analysis, a number of protocols were applied from a holding potential of $-90 \mathrm{mV}$ with a start-to-start interval of $0.2 \mathrm{~Hz}$. Sodium current traces were evoked by $100 \mathrm{~ms}$ depolariarions to $V_{\max }$ (the voltage corresponding to maximal sodium current in control conditions). The current-voltage relationships were determined by $50-\mathrm{ms}$ step depolarization between -90 and $70 \mathrm{mV}$, using $5-m V$ increments. The sodium conductance $\left(g_{\mathrm{Na}}\right)$ was calculated from the currents according to Ohm's law: $g_{\mathrm{Na}}=I_{\mathrm{Na}} /\left(V-V_{\text {rev }}\right)$, where $I_{\mathrm{Na}}$ represents the $\mathrm{Na}^{+}$current peak amplitude at a given test potential $V$, and $V_{\text {rev }}$ is the reversal potential. The values of $g_{\mathrm{Na}}$ were plotted as a function of voltage and fitted using the Boltzmann equation: $g_{\mathrm{Na}} / g_{\max }=$ $\left[1+\left(\exp \left(V_{\mathrm{g}}-V\right) / k\right)\right]^{-1}$, where $g_{\max }$ represents maximal $g_{\mathrm{Na}}, V_{\mathrm{g}}$ is the voltage corresponding to half-maximal conductance and $k$ is the slope factor. Toxin-induced effects on the steady-state inactivation were investigated with a standard two-step protocol. In this protocol, 100-ms conditioning $5-\mathrm{mV}$ step prepulses ranging from -90 to $70 \mathrm{mV}$ were followed by a $50-\mathrm{ms}$ test pulse to -30 or $-10 \mathrm{mV}$. Data were normalized to the maximal $\mathrm{Na}^{+}$current amplitude, plotted against prepulse potential and fitted using the Boltzmann equation: $I_{\mathrm{Na}} I_{\max }=[(1-C) /(1+$ $\left.\left.\exp \left(\left(V-V_{\mathrm{h}}\right) / k\right)\right)\right]+C$, where $I_{\max }$ is the maximal $I_{\mathrm{Na}}, V_{\mathrm{h}}$ is the voltage corresponding to half-maximal inactivation, $V$ is the test voltage, $k$ is the slope factor, and $C$ is a constant representing a noninactivating persistent fraction (close to zero in control). The recovery from inactivation was assayed with a double-pulse protocol, where a 100-ms conditioning pulse to -30 or $-10 \mathrm{mV}$ was followed by a 50 -ms test pulse to the same voltage. Both pulses were interspersed by a repolarization to -90 $\mathrm{mV}$ for a gradually increasing time interval $(1-40 \mathrm{~ms})$. The $I_{\mathrm{Na}}$ obtained in the test pulse was normalized to the $I_{\mathrm{Na}}$ obtained in the conditioning pulse, plotted against the corresponding time interval and fitted with the following exponential equation: $f(t)=A e^{-t / \tau}+C$, where $t$ represents the time, $A$ is the amplitude of the current, $\tau$ is the time constant for the fast inactivation, and $C$ is a constant representing a noninactivating persistent fraction (close to zero in control).

To assess the concentration dependence of the MeuNaTx $\alpha$ s-induced effects, dose-response curves were constructed. To quantify the toxin induced slowing down of inactivation, the relative $I_{30 m s} / I_{\text {peak }}$ values were plotted against the applied concentrations. The data were fitted with the Hill equation: $y=100 /\left[1+\left(E C_{50} /[\text { toxin }]\right)^{h}\right]$, where $y$ is the amplitude of the toxin-induced effect, $E C_{50}$ is the toxin concentration at half maximal efficacy, [toxin] is the toxin concentration and $h$ is the Hill coefficient. The time constants $(\tau)$ of the VGSC fast inactivation were measured directly from the decay phase of the recorded $\mathrm{Na}^{+}$current using a single exponential fit. Comparison of two sample means was made using a paired Student's $t$ test $(p<$ 0.05). All data are presented as means \pm S.E. (S.E.) of at least five independent experiments $(n \geq 5)$. All data was analyzed by pClamp Clampfit 10.0 (Molecular Devices) and Origin 7.5 software (Originlab, Northampton, MA).

Insect Toxicity Assays - Insect toxicity assays were performed according to the method of Maggio and King (26). Briefly, MeuNaTx $\alpha-4$ with twofold dilution by insect saline was injected into house flies (Musca domestica TJS, deltamethrin-sensitive strain; and M. domestica BJD, deltamethrin-resistant strain) (27) for toxicity assays. Each fly (about $10 \mathrm{mg}$ ) was injected with $1 \mu \mathrm{l}$ of toxin at a dose of $0.14,0.28$, $0.56,1.12,2.25,4.5,9$, or $18 \mathrm{pmol}$ and the flies injected with $1 \mu \mathrm{l}$ of insect saline were used as control. Ten flies were used for each toxin dose. Experiments were performed in duplicate. Half maximal lethal dose $\left(L_{50}\right)$ values at $24 \mathrm{~h}$ postinjection were calculated from the dose-response data by OriginPro 7.5.

Maximum Likelihood Analysis-The $\alpha$-toxins used here include 34 sequences: $13 \mathrm{M}$. eupeus sequences reported here and $21 \mathrm{M}$. martensii sequences retrieved from the GenBank database (http:// www.ncbi.nlm.nih.gov/). Nucleotide sequences of these toxins were aligned according to their amino acid alignment, where sites containing gaps were excluded in this analysis. Aligned nucleotide sequences of Mesobuthus $\alpha$-toxins for analysis of positive selection are provided in the supplementary Appendix. Ratios of nonsynonymous to synonymous rates of substitution $(\omega=\mathrm{d} N / \mathrm{d} S)$ between pairs of genes were calculated by the method of Nei and Gojobori 1986 (28). A neighbor-joining tree constructed by MEGA 3.1 (http://www. megasoftware.net) was used for further statistical analysis. The CODEML program of the PAML software package (http://abacus. gene.ucl.ac.uk/software/paml.html) (29) was used to estimate $\omega$ values, in which four models were used to make two likelihood ratio tests (LRTs) by M1a/M2a and M7/M8: M1a (nearly neutral model) constraints a proportion $\mathrm{p} 0$ of conserved sites with $0<\omega 0<1$, whereas a proportion $\mathrm{p} 1=1-\mathrm{p} 0$ of neutral sites with $\omega 1=1$; M2a (positive selection model) adds an extra class of sites with the proportion $\mathrm{p} 2=$ $1-\mathrm{p} 0-\mathrm{p} 1$ and with $\omega 2$ estimated from the data. M7 ( $\beta$ distribution model) does not allow for positively selected sites (PSSs) and M8 ( $\beta$ and $\omega$ model) adds an extra class of sites to M7, allowing for $\omega>1$, which means the presence of PSSs. Upon detection of the positively selected signals, the calculation of posterior probabilities was completed using the empirical Bayes method. 

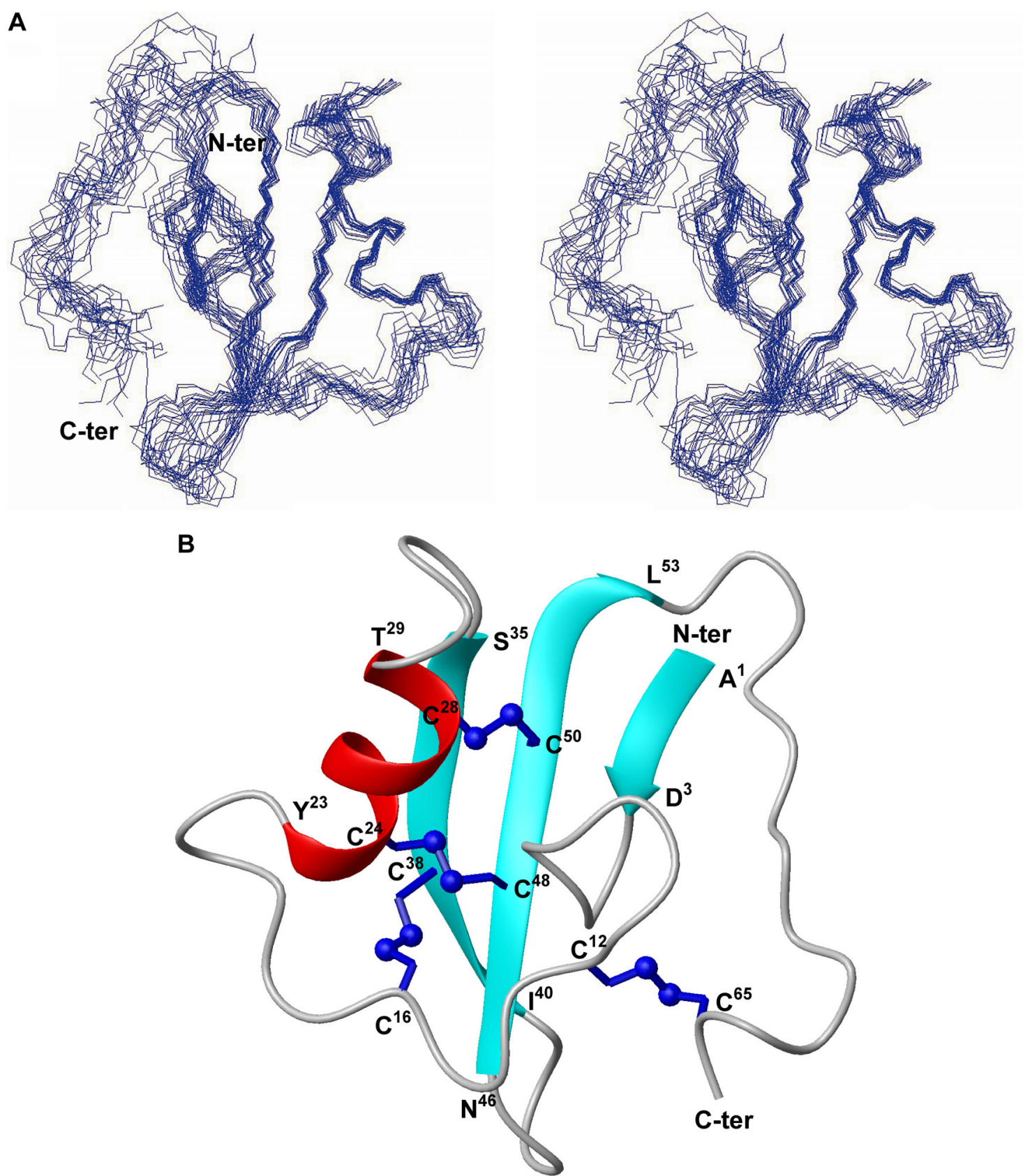

FIG. 5. Solution structure of MeuNaTx $\alpha-5$. A, Stereo view of the 20 NMR models, superimposed for a minimum r.m.s.d. to the (C, $\mathrm{C}_{\alpha}$, $\mathrm{N})$ atoms from residues Ala1 to His66; $B$, Ribbon representation of the toxin. Disulfide bridges (SS1-SS4) are shown in a blue stick model. Secondary structure regions are assigned by STRIDE (http://webclu.bio.wzw.tum.de/stride/). Beginning and ending amino acids of each secondary structure element ( $\alpha$-helix in red and $\beta$-strand in cyan) are labeled according to the peptide sequence.

Homology Modeling of Structures of $\mathrm{DmNa}_{v} 1$-For modeling the structure of $\mathrm{DmNa}_{v} 1$, sequences of segments $\mathrm{S} 1-\mathrm{S} 6$ of this channel domains I-IV (residues Asn ${ }^{140}-$ Ala $^{439}$ for DI; Phe ${ }^{816}-$ Asn $^{1042}$ for DII; $\mathrm{Tyr}^{1302}$-Gly ${ }^{1557}$ for DIII; Arg $^{1607}$-GIn ${ }^{1871}$ for DIV) were aligned using ClustalX software with the paddle-chimaera channel, a chimeric voltage-gated potassium channel, in which the voltage-sensor paddle has been transferred from $\mathrm{K}_{\mathrm{v}} 2.1$ to $\mathrm{K}_{\mathrm{v}} 1.2$ (30). All the alignments were then manually adjusted using secondary structure element information predicted from SOMPA (http://www.expasy.org) and the paddle-chimaera channel voltage sensor structure. To obtain a model of each domain, aligned sequences (for details, see supplemental Fig. S1) were input into Homer, a fully automated protein structure homology-modeling server (http://protein.cribi.unipd.it/homer/). The $\mathrm{DmNa}_{\mathrm{v}} 1$ structure comprising $\mathrm{S} 1-\mathrm{S} 6$ of all the four domains were assembled in a clockwise arrangement manner according to the architecture of the paddle-chimaera channel (pdb entry 2R9R).

\section{RESULTS}

Isolation of a Multigene Family of $\alpha$-Toxins in $M$. eupeus-To isolate a multigene family of $\alpha$-toxins in $M$. eupeus, 


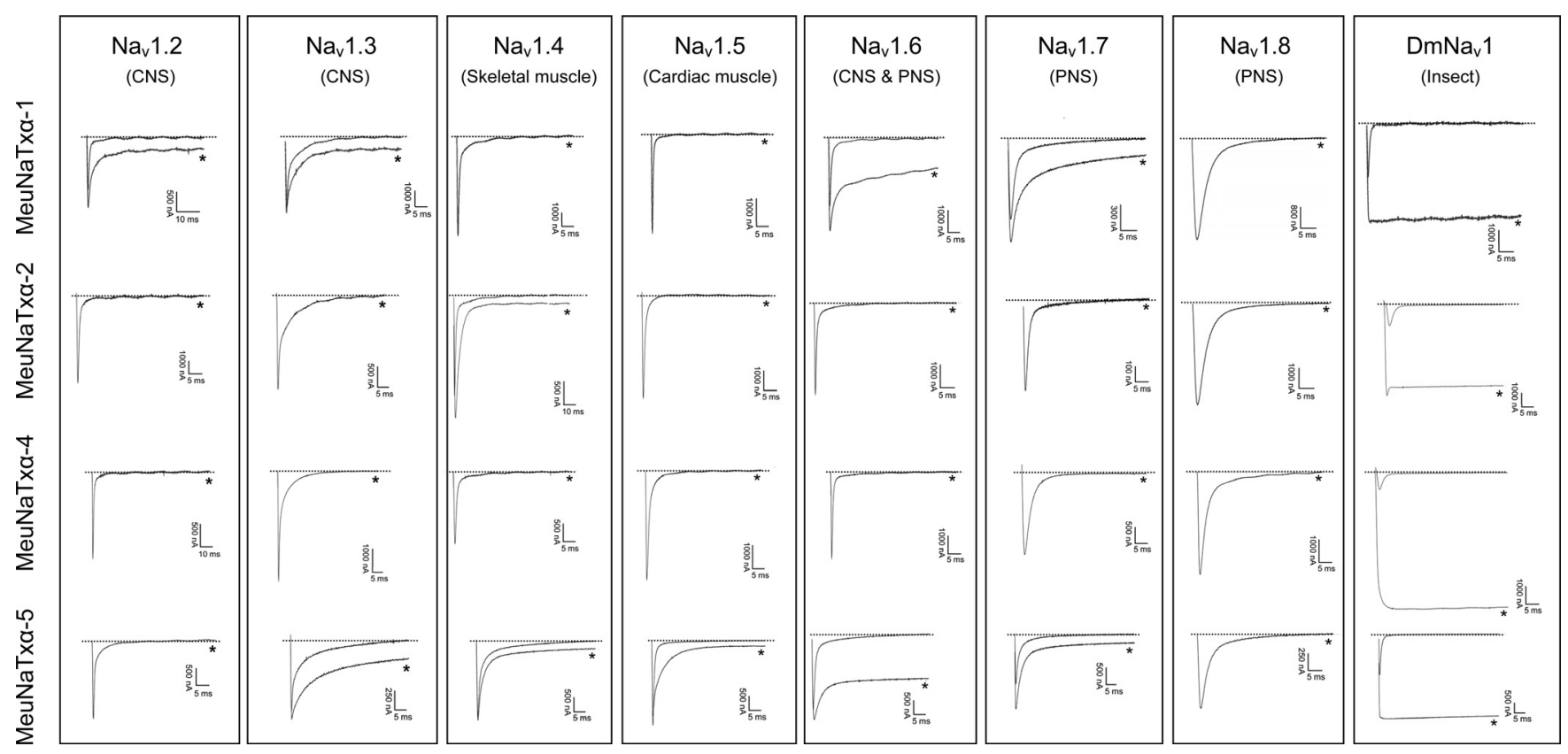

FIG. 6. Differential effects of MeuNaTx $\alpha-1,-2,-4$, and -5 on $\mathrm{Na}_{\mathbf{v}}$ isoforms expressed in $X$. leavis oocytes. Representative whole cell $\mathrm{Na}^{+}$ current traces of oocytes expressing cloned $\mathrm{Na}_{v}$ isoforms $\left(\mathrm{Na}_{v} 1.2-\mathrm{Na}_{\mathrm{v}} 1.8\right.$, and $\left.\mathrm{DmNa}_{\mathrm{v}} 1\right)$ are shown. The dotted line indicates the zero-current level. The ${ }^{*}$ indicates the steady-state current peak amplitude in the presence of 1-2 $\mu \mathrm{M}$ toxin. CNS: central nervous system; PNS: peripheral nervous system.

we designed multiple forward and reverse primers based on known sequence information from different regions of $\alpha$-toxins for $3^{\prime}$ and $5^{\prime}$ RACE (Fig. $1 A$ ) and genomic amplification, from which a total of 13 different toxin genes were cloned and their sequences were shown in Fig. 1B. We name these toxins MeuNaTx $\alpha-1$ to MeuNaTx $\alpha-13$, all of which contain 8 conserved cysteines that form 4 disulfide bridges. In addition to the cysteines, there are 13 other residues $\left(\mathrm{Arg}^{2}, \mathrm{Ile}^{6}, \mathrm{Gly}^{30}\right.$, $\mathrm{Ala}^{31}, \mathrm{Ser}^{33}, \mathrm{Gly}^{34}, \mathrm{Gly}^{43}, \mathrm{Asn}^{44}, \mathrm{Leu}^{51}, \mathrm{Pro}^{52}, \mathrm{Val}^{55}, \mathrm{Pro}^{56}$, and $11 e^{57}$, all sites of toxins described in this study numbered according to MeuNaTx $\alpha-1$ ) which are exactly conserved across the alignment of the multigene family. Most residues identified here are likely associated with structural stabilization of $\alpha$-toxins. For example, $\mathrm{Arg}^{2}$ and $\mathrm{Val}^{55}$ have been found to form hydrogen bonds between their sidechains; $11 \mathrm{e}^{6}, \mathrm{Leu}^{51}, \mathrm{Pro}^{52}$, and $\mathrm{Val}^{55}$ constitute part of the hydrophobic core of $\alpha$-toxins; $\mathrm{Ala}^{31}$ acts as a key residue that is involved in the tight turn connecting the $\alpha$-helix to the $\beta$-sheet; Gly $^{34}$, a highly conserved residue in scorpion toxins and insect defensins, has an important role in minimizing the steric hindrance involved in the $\operatorname{CS} \alpha \beta$ motif (31). Mutations at sites $\mathrm{Arg}^{2}, \mathrm{Ile}^{6}, \mathrm{Gly}^{34}$, Leu ${ }^{51}$, and Pro ${ }^{52}$ of BmKM1 have been found to markedly affect the structural stability of this toxin (32).

Despite structural residue conservation, the carboxyl termini of MeuNaTx $\alpha$ s exhibit extensive sequence diversity, in which four peptides (MeuNaTx $\alpha-1,-2,-7$, and -9) may be amidated because of the presence of Gly-Arg or Gly in the C terminus of their precursors, as previously observed in other animal toxins, e.g. the scorpion sodium channel toxin TsV (33) and bee venom peptides apamin and melittin $(34,35)$. For most other MeuNaTx $\alpha$ s, the C-terminal 1-2 arginine residues will be removed. In addition, MeuNaTx $\alpha$-3 contains an unusual C-terminal sequence His-Leu-Gln, as compared with other $\alpha$-toxins. Based on the size of the J-loop preceding the conserved $\alpha$-helix, MeuNaTx $\alpha$ s can be divided into three distinct groups: (1) MeuNaTx $\alpha-1,-2,-7,-9$ and -12 , which all have a five-residue $\mathrm{J}$-loop, as oberved in most known $\alpha$-toxins; (2) MeuNaTx $\alpha-4,-5,-6,-8,-10,-11$, and -13 , which contains an insertion of two hydrophobic residues (Ala-Phe) in the J-loop relative to the first group; (3) MeuNaTx $\alpha$-3 whose J-loop extends a hydrophilic eight-residue segment $\left({ }^{19} \mathrm{Glu}-\right.$ Tyr-Thr-Tyr-Ile-Gly-Thr-Ser ${ }^{26}$ ). Given the J-loop carries crucial functional residues in several $\alpha$-toxins (e.g. Lqh $\alpha$ IT and Lqh2) $(36,37)$, it is assumed that these changes in size could be associated with the divergence of MeuNaTx $\alpha$ s, if any, by introducing a novel chemical environment (hydrophilic) into this binding loop of $\alpha$-toxins, as previously observed in convergent evolution of novel function in serine proteases of shrew and lizard venom (38).

We also determined the genomic organization of three MeuNaTx $\alpha$ s, i.e. MeuNaTx $\alpha-1$, MeuNaTx $\alpha-2$, and MeuNaTx $\alpha-$ 5', which all share a conserved exon-intron structure, as observed previously for some known $\alpha$-toxins, where an intron disrupts the coding-region of the signal peptide end (39). Despite differing in size, the sequences around $5^{\prime}$ and $3^{\prime}$ splice signals of these toxins are highly similar (Fig. $2 A$ and $2 B$ ). 
A
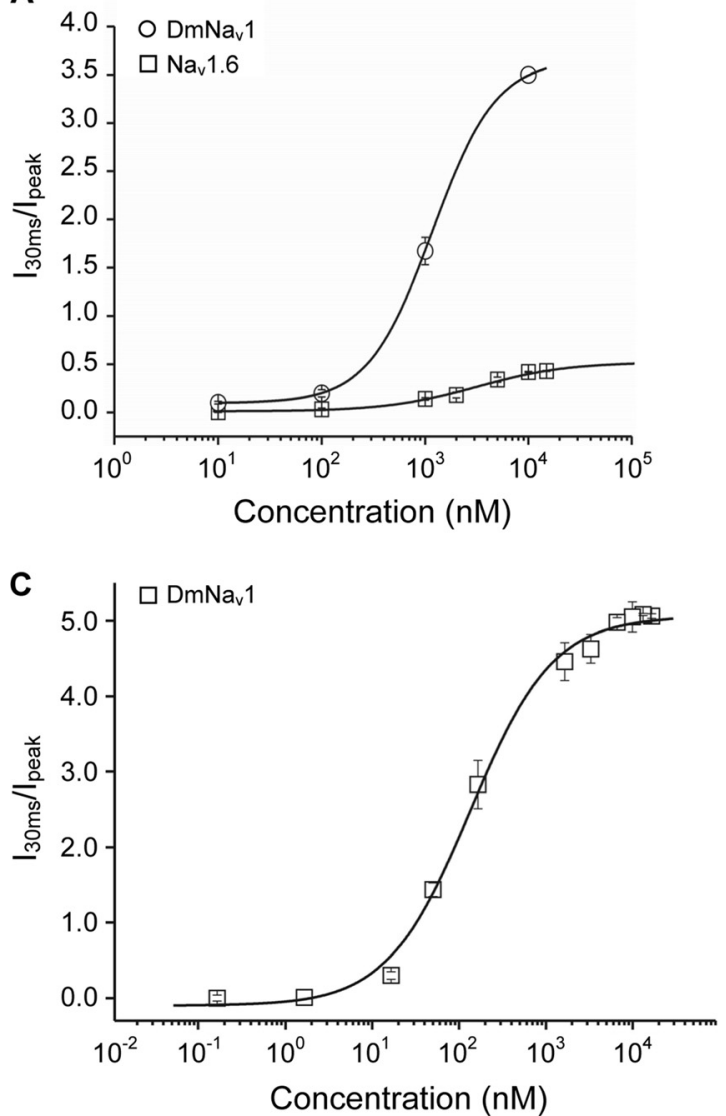
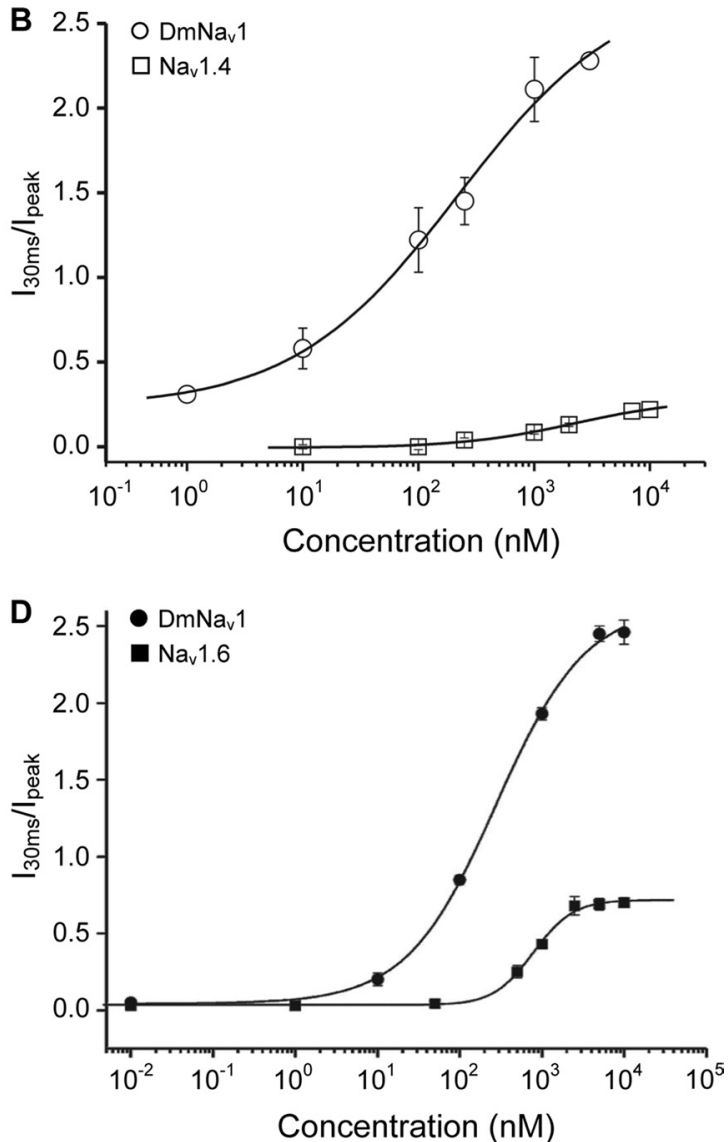

FIG. 7. Dose-response curves of $\boldsymbol{M}$. eupeus $\boldsymbol{\alpha}$-toxins. The curves were obtained by plotting the relative $\mathrm{I}_{30} \mathrm{~ms} / \mathrm{I}_{\text {peak }}$ values of the channels in function of the toxin concentrations. All the curves were fitted with the Hill equation. $A$, MeuNaTx $\alpha-1$ on $\mathrm{DmNa}_{\mathrm{v}} 1$ and $\mathrm{Na}_{\mathrm{v}} 1.6 ; B, \mathrm{MeuNaTx}-2$ on $\mathrm{DmNa}_{\mathrm{v}} 1$ and $\mathrm{Na}_{\mathrm{v}} 1.4 ; \mathrm{C}$, MeuNaTx $\alpha-4$ on $\mathrm{DmNa}_{\mathrm{v}} 1 ; D$, MeuNaTx $\alpha-5$ on $\mathrm{DmNa}_{\mathrm{v}} 1$ and $\mathrm{Na}_{\mathrm{v}} 1.6$.

TABLE III

Effects of Mesobuthus eupeus toxins on mammalian $\mathrm{Na}_{v} 1.2-\mathrm{Na}_{v} 1.8$ and Drosophila sodium channels. N.A. means no activity at 1 uM for MeuNaTx $\alpha-1$ - MeuNaTx $\alpha-3$ and $2 \mu$ m for MeuNaTx $\alpha$-4. "Weak" indicates far smaller than $50 \%$ steady-state current peak amplitude at $1 \mu M$ for MeuNaTx $\alpha-1$ - MeuNaTx $\alpha-3$, and $2 \mu \mathrm{M}$ for MeuNaTx $\alpha-4$ and MeuNaTx $\alpha-5$. The $50 \%$ effective concentration (EC $50, \mu M)$ values indicating high affinity are boldfaced

\begin{tabular}{|c|c|c|c|c|c|c|c|c|}
\hline & Nav1.2 & Nav1.3 & Nav1.4 & Nav1.5 & Nav1.6 & Nav1.7 & Nav1.8 & DmNav1 \\
\hline MeuNaTx $\alpha-1$ & weak & weak & N.A. & N.A. & $3.10 \pm 1.14$ & weak & N.A. & $1.17 \pm 0.15$ \\
\hline MeuNaTx $\alpha-2$ & N.A. & N.A. & $2.23 \pm 0.45$ & N.A. & N.A. & N.A. & N.A. & $0.22 \pm 0.13$ \\
\hline MeuNaTx $\alpha-4$ & N.A. & N.A. & N.A. & N.A. & N.A. & N.A. & N.A. & $0.13 \pm 0.02$ \\
\hline
\end{tabular}

Phylogenetic Analysis of Mesobuthus NaScTxs-To elucidate the evolutionary relationship of Mesobuthus NaScTxs, we reconstructed a phylogeny of the toxins from their nucleotide sequences using the Neighbor-Joining algorithm with the Maximum Composite Likelihood model and 1000 bootstrap replicates (Fig. 3). From the topology of the phylogeny, we can recognize five well-defined clades (I to V), all with over $90 \%$ bootstrap support except for clade I. Of them, I and V are two large clades containing multiple toxins from both $M$. eupeus and M. martensii, supporting their orthologous relationship, whereas II, III, IV consist of less sequences. Clade I includes most of $M$. eupeus toxins and several toxins from $M$. martensii, in which BmKM1, an $\alpha$-like toxin with activity on both insect and mammalian VGSCs, can be considered as the prototype of this clade (32). Members in clade III have been found to evolve distinct functional feature that exhibits nitrergic actions (40). Clade 4 only includes two $M$. eupeus toxins (MeuNaTx $\alpha-2$ and -9) with the closest distance to Clade 5 that contains BmK $\alpha \mathrm{IV}$, a functional hybrid of $\alpha$-toxins (41).

Purification and Characterization of Four MeuNaTx $\alpha$ s-To structurally and functionally characterize $M$. eupeus $\alpha$-NaScTxs, we isolated five native peptides from $M$. eupeus venom by RP-HPLC, which respectively correspond to 
A

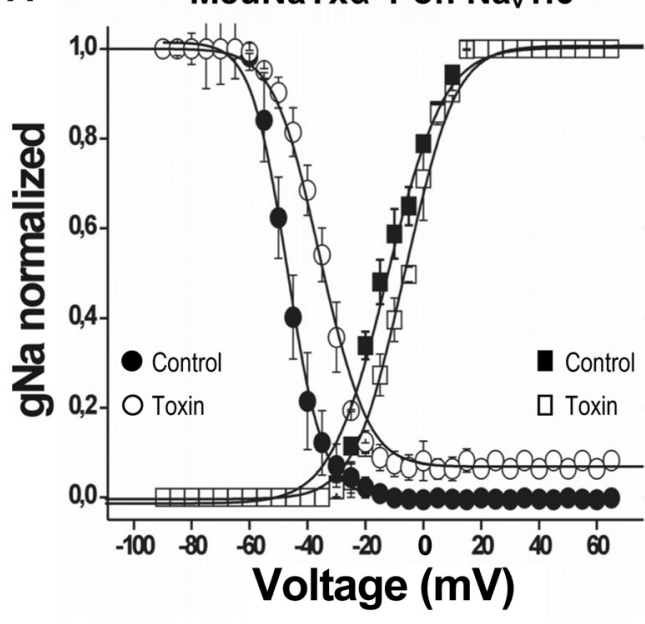

B

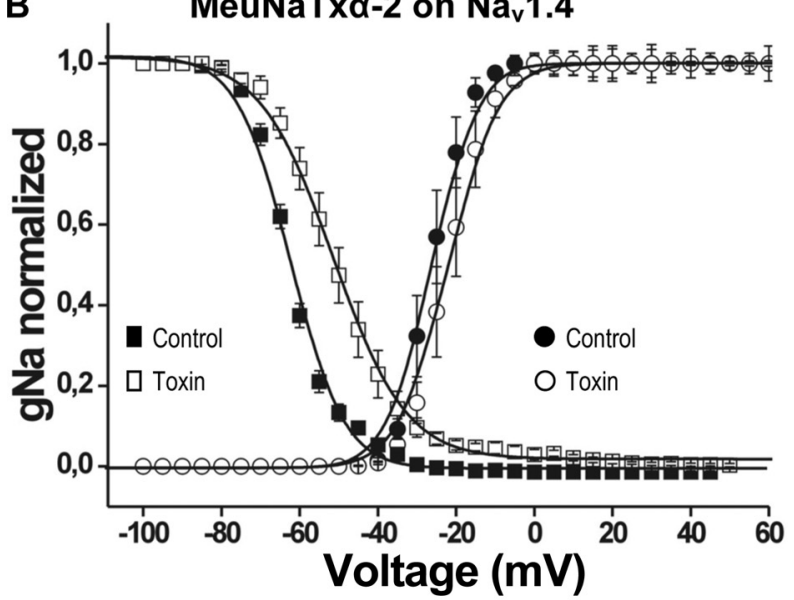

C

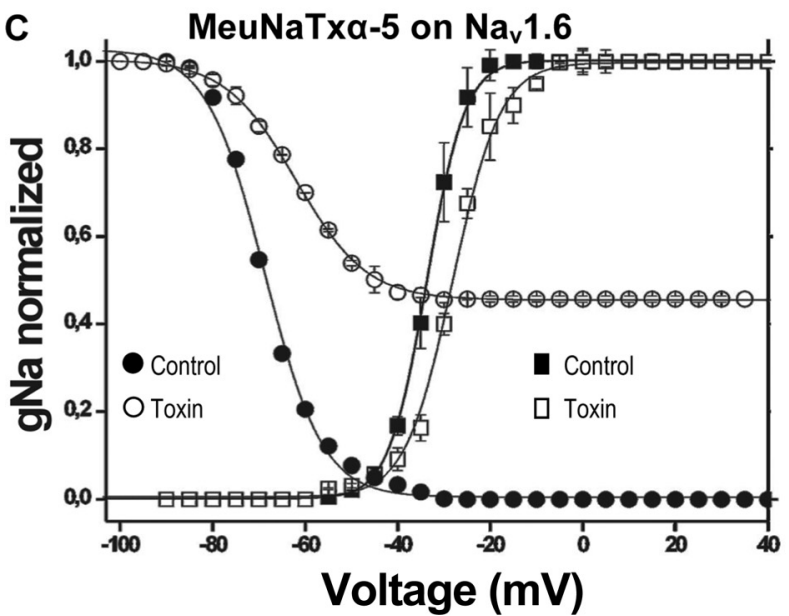

MeuNaTxa-1 on $\mathrm{DmNa}_{\mathrm{v}} 1$
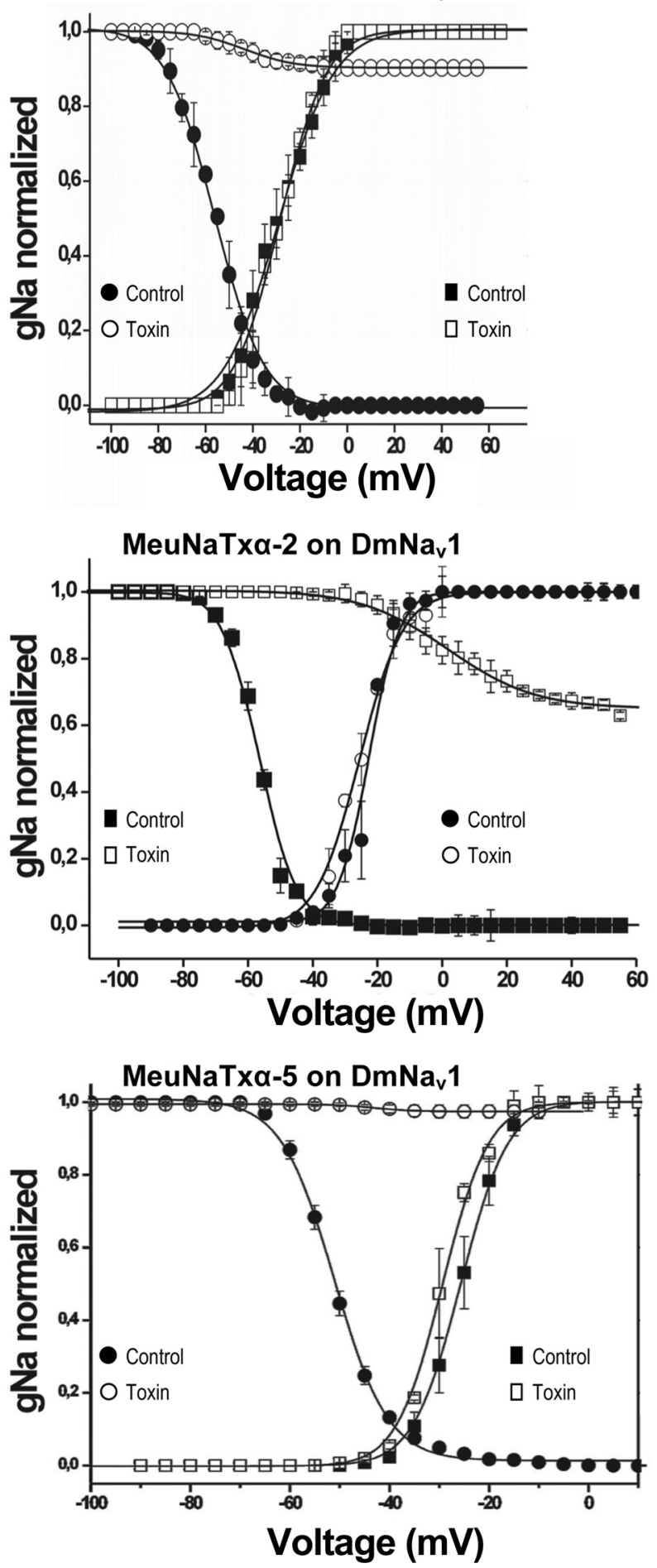

FIG. 8. Effects of $M$. eupeus $\boldsymbol{\alpha}$-toxins on the voltage dependence of activation and steady-state inactivation curves of $\mathrm{Na}_{\mathrm{v}}$ channels. The steady-state currents of the channels in control and after the addition of $1 \mu \mathrm{M}$ toxin are shown. $A, \mathrm{MeuNaTx}-1: \mathrm{Na}_{\mathrm{v}} 1.6(l e f t)$ and $\mathrm{DmNa} 1$ (right); $B$, MeuNaTx $\alpha-2: \mathrm{Na}_{\mathrm{v}} 1.4$ (left) and DmNa 1 (right); C, MeuNaTx $\alpha-5: \mathrm{Na}_{\mathrm{v}} 1.6$ (left) and $\mathrm{DmNa}_{\mathrm{v}} 1$ (right).

MeuNaTx $\alpha-1$ to MeuNaTx $\alpha-5$ predicted from their gene sequences (Fig. 1). MeuNaTx $\alpha-1$ to MeuNaTx $\alpha-5$ were eluted as single peaks at retention time $\left(T_{R}\right)$ of $38.2,42.2,43.5,44.0$, and $44.4 \mathrm{~min}$, respectively (Fig. 4). Their purities and molec- ular masses were confirmed by MALDI-TOF (Table I; supplemental Fig. S2). Experimental masses for these peptides are 7178.27, 7233.68, 8299.90, 7199.55, and 7170.47 $\mathrm{Da}$, respectively, perfectly matching the theoretical masses 

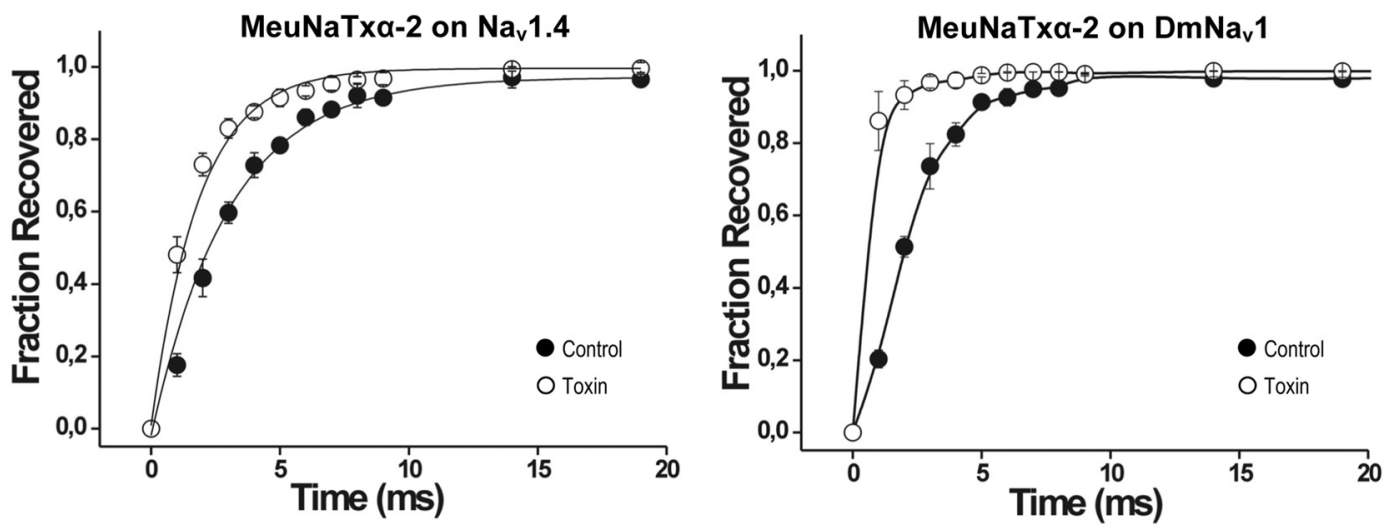

FIG. 9. Effects of MeuNaTx $\alpha-2$ on the recovery from fast inactivation of $\mathrm{Na}_{\mathbf{v}}$ channels. $\mathrm{Na}_{\mathrm{v}} 1.4$ (left) and $\mathrm{DmNa} \mathrm{v}_{\mathrm{v}} 1$ (right) in control and in the presence of $1 \mu \mathrm{m}$ peptide are shown.

calculated from their primary sequences $(7177.12,7233.19$, 8298.31, 7199.27, and 7171.22 Da, respectively). Amino-terminal sequences of MeuNaTx $\alpha-1,-2,-4$, and -5 were determined by Edman degradation, which are completely identical to those deduced from their gene sequences (Table I; Fig. 1).

NMR Structure of MeuNaTx $\alpha-5$-The solution structure of MeuNaTx $\alpha-5$ was solved by proton NMR spectroscopy at $\mathrm{pH}$ 4.0. Twenty models superposed with all backbone atoms ( $N$, $\mathrm{C}_{\alpha}$, and $\mathrm{C}$ ) have a root-mean-square deviation (r.m.s.d.) of $1.50 \pm 0.20 \AA$ to the mean structure, and this value is $2.11 \pm$ $0.20 \AA$ when all heavy atoms are superimposed (Table II). The corresponding values for secondary structural region are $0.52 \pm 0.15 \AA$ and $0.92 \pm 0.20 \AA$, indicating that these regions are more stable than the loops. Among the 20 converged structures (Fig. $5 A$ ), $77.2 \%$ of the residues fall within the most favored regions of the Ramachandran plot, $16.9 \%$ within additional allowed regions, and $5.4 \%$ within generously allowed regions, and only $0.6 \%$ within disallowed regions. Not surprisingly, the overall fold of MeuNaTx $\alpha-5$ is similar to other scorpion $\alpha$-toxins, which is composed of an $\alpha$-helix $\left(\operatorname{Tyr}^{23}\right.$ to $\mathrm{Thr}^{29}$ ) and three anti-parallel $\beta$-strands ( $\beta 1$ : $\mathrm{Ala}^{1}$ to $\mathrm{Asp}^{3} ; \beta 2$ : $\mathrm{Ser}^{35}$ to $11 \mathrm{e}^{40} ; \beta 3$ : $\mathrm{Asn}^{46}$ to $\mathrm{Leu}^{53}$ ), and is stabilized by four disulfide bridges (Cys ${ }^{12}-$ Cys $^{65}$, Cys $^{16}-$ Cys $^{38}$, Cys ${ }^{24}-$ Cys $^{48}$ and Cys $^{28}-$ Cys $^{50}$ ) (Fig. 5B).

Channel Subtype Selectivity of MeuNaTx $\alpha$ s-The eight cloned VGSCs $\left(\mathrm{Na}_{\mathrm{v}} 1.2-\mathrm{Na}_{\mathrm{v}} 1.8\right.$ from mammals and $\mathrm{DmNa}_{\mathrm{v}} 1$ from Drosophila) expressed in Xenopus laevis oocytes were used for evaluation of pharmacological functions of four MeuNaTx $\alpha$ s (-1, -2, -4 , and -5$)$ by using the two-electrode voltage clamp technique. MeuNaTx $\alpha-3$ is not functionally evaluated because of its low abundance in the venom. As shown in Fig. 6, $\mathrm{DmNa}_{\mathrm{v}} 1$ is the most sensitive channel of MeuNaTx $\alpha$ s since its inactivation process is completely impaired by all the four peptides at 1-2 $\mu \mathrm{M}$ concentration. At these two concentrations, all the peptides did not affect $\mathrm{Na}_{\mathrm{v}} 1.8$ but differentially affected other six mammalian VGSC isoforms (Fig. 6). MeuNaTx $\alpha$ s induced slowing of inactivation of VGSCs in a concentration-dependent manner (Fig. 7). The
$50 \%$ effective concentration $\left(E_{50}\right)$ values of these toxins on sensitive channels were determined with a Boltzmann sigmoidal fit of the obtained data. For $\mathrm{DmNa}_{\mathrm{v}} 1$, the $\mathrm{EC}_{50}$ values are $1.17 \pm 0.15 \mu \mathrm{M}$ for MeuNaTx $\alpha-1 ; 0.22 \pm 0.13 \mu \mathrm{M}$ for MeuNaTx $\alpha-2 ; 0.13 \pm 0.02 \mu \mathrm{M}$ for MeuNaTx $\alpha-4 ; 0.28 \pm 0.04$ $\mu \mathrm{M}$ for MeuNaTx $\alpha-5$ (Table III). MeuNaTx $\alpha-1$ and -5 obviously lack selectivity because they display some affinity for multiple mammalian VGSC isoforms. MeuNaTx $\alpha-1$ impaired the inactivation process of $\mathrm{Na}_{v} 1.2,1.3,1.6,1.7$ whereas MeuNaTx $\alpha-5$ affected $\mathrm{Na}_{\mathrm{v}} 1.3,1.4,1.5,1.6,1.7$. The $\mathrm{EC}_{50}$ values of MeuNaTx $\alpha-1$ for $\mathrm{Na}_{v} 1.6$ are $3.10 \pm 1.14 \mu \mathrm{M}$ and MeuNaTx $\alpha-5$ for $\mathrm{Na}_{v} 1.6$ is $0.79 \pm 0.06 \mu \mathrm{M}$. Among seven mammalian VGSCs, $\mathrm{Na}_{v} 1.4$ is the only one isoform affected by MeuNaTx $\alpha-2$ with an $\mathrm{EC}_{50}$ of $2.23 \pm 0.45 \mu \mathrm{M}$. MeuNaTx $\alpha-4$ is the only one insect-specific toxin characterized in the Mesobuthus lineage. Its insect toxicity was verified by in vivo assays on Musca domestica that showed a half lethal dose $\left(\mathrm{LD}_{50}\right)$ values of $204.18 \pm 23.73 \mathrm{pmol} \mathrm{g}^{-1}$ on $M$. domestica TJS (deltamethrin-sensitive strain) and $194.57 \pm 12.56 \mathrm{pmol}$ $\mathrm{g}^{-1}$ on $M$. domestica BJD (deltamethrin-resistant strain, $k d r$ and super-kdr). Although $k d r$ (Leu1014Phe) and super-kdr (M918T) mutations in the BJD $\mathrm{Na}^{+}$channel may be a cause of resistance to deltamethrin (27), these two changes did not influence the binding of MeuNaTx $\alpha-4$ to the BJD Na+ channel, indicating the receptor difference between scorpion $\alpha$-toxins and the pesticide deltamethrin (site 3 versus site 7 ). Overall, MeuNaTx $\alpha-1,-2$ and -5 can be considered as $\alpha$-like toxins but with a preference for the insect VGSC.

Effects of MeuNaTx $\alpha$ s on the voltage dependence of activation and steady-state inactivation of sensitive VGSCs were also investigated (Fig. 8). The results show that $1 \mu \mathrm{M}$ toxin (MeuNaTx $\alpha-1$ on $\mathrm{Na}_{v} 1.6$ and $\mathrm{DmNa}_{v} 1$; MeuNaTx $\alpha-2$ on $\mathrm{Na}_{\mathrm{v}} 1.4$ and $\mathrm{DmNa}_{\mathrm{v}} 1$; and MeuNaTx $\alpha-5$ on $\mathrm{Na}_{\mathrm{v}} 1.6$ and Dm$\left.\mathrm{Na}_{v} 1\right)$ do not significantly $(p<0.05)$ shift the midpoint of activation at the channels, but the same concentration of toxin induced a significant $(p<0.05)$ depolarizing shift in the $V_{1 / 2}$ of inactivation of the channels. In addition, we examined the recovery from fast inactivation in the absence or presence of 


\begin{tabular}{|c|c|c|c|c|c|c|c|c|c|c|c|c|c|c|c|c|c|c|c|c|c|c|c|c|c|c|c|c|c|c|c|c|c|}
\hline \multicolumn{34}{|l|}{ MeuNaTxa-9 } \\
\hline MeuNaTxa-2 & & & & & & & & & & & & & & & & & & & & & & & & & & & & & & & & & $\ddot{0}$ \\
\hline BmaTX19 & & & & & & & & & & & & & & & & & & & & & & & & & & & & & & & & & $\ddot{0}$ \\
\hline BmKaTX11 & & & & & & & & & & & & & & & & & & & & & & & & & & & & & & & 8 & |c & \begin{tabular}{|l|}
0 \\
0
\end{tabular} \\
\hline BmKTa & & & & & & & & & & & & & & & & & & & & & & & & & & & & & & $\because$ & $\because=$ & : & m? \\
\hline BmKa1 & & & & & & & & & & & & & & & & & & & & & & & & & & & & & ?: & 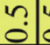 & 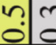 & $?$ & $\begin{array}{l}m \\
0 \\
0\end{array}$ \\
\hline BmKaTx15 & & & & & & & & & & & & & & & & & & & & & & & & & & & & & ?.: & $:$ & :̇e & $?$ & ma \\
\hline BmKalV & & & & & & & & & & & & & & & & & & & & & & & & & & & 8 & @ & 87 & $\tilde{0}$ & 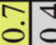 & 官. & $\stackrel{+}{0}$ \\
\hline BmaTx18 & & & & & & & & & & & & & & & & & & & & & & & & & & & 8 & ? & 87 & 5 & $\begin{array}{l}\infty \\
0 \\
0\end{array}$ & ¿. & $\stackrel{+}{\circ}$ \\
\hline MeuNaTxa-7 & & & & & & & & & & & & & & & & & & & & & & & & & $\ddot{0}$ & $\ddot{0}$ & 0 & $\ddot{0}$ & : & ? & 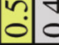 & 5 & ثั. \\
\hline MeuNaTxa-1 & & & & & & & & & & & & & & & & & & & & & & & & $\overrightarrow{0}$ & 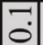 & 7 & 7 & $\overline{0}$ & \begin{tabular}{|c|c}
0 \\
0
\end{tabular} & $\tilde{n}$ & $\begin{array}{c}+ \\
0.0\end{array}$ & ?3? & ? \\
\hline BmKaTx17 & & & & & & & & & & & & & & & & & & & & & & & $\stackrel{+}{0}$ & 范 & 官 & 官 & 官 & ? & $\because$ & $\hat{0}$. & & o. & 0 \\
\hline MeuNaTxa-12 & & & & & & & & & & & & & & & & & & & & & & $\infty$ & ? & $\mid$ & 官 & 官 & : & ? & $\begin{array}{c}n \\
0\end{array}$ & 0.1 & & & 9 \\
\hline BmKaTx10 & & & & & & & & & & & & & & & & & & & & & & ב & $\stackrel{0}{0}$ & 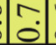 & $\mid \begin{array}{l}0 \\
0 \\
0\end{array}$ & $\mid$ & $n$ & $\stackrel{0}{0}$ & $\ddot{0} 0$ & $\hat{0}$. & 웅. & & 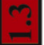 \\
\hline BmaTx9 & & & & & & & & & & & & & & & & & & & & & $?$ & : & : & ? & ?n & $\begin{array}{l}n \\
0 \\
0\end{array}$ & ? & ?? & $\begin{array}{lll}n & 0 \\
0 & 0 & 0\end{array}$ & 9.0 & $\infty$ & & อి \\
\hline BmKM11 & & & & & & & & & & & & & & & & & & & & & a & م. & ? & ?? & : & 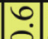 & n? & $n$ & n: & 9.6 & ?. & & - \\
\hline BmKaTx13 & & & & & & & & & & & & & & & & & & & $\begin{array}{l}\infty \\
0 . \\
0\end{array}$ & & 70 & 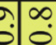 & 苟. & ? & ?n: & | & ? & ? & ?:0 & $\begin{array}{lll}\infty & \\
0 & & \\
0 & \end{array}$ & $\infty$ & & 웅. \\
\hline BmaTx14 & & & & & & & & & & & & & & & & & & & a. & & 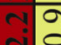 & कृ & 8 & ?? & $?$ & $\because$ & ? & ? & n'c & बेद & a. & & $\hat{0}$ \\
\hline BmK22 & & & & & & & & & & & & & & & & & 8 & & $\begin{array}{l}\infty \\
0 \\
0\end{array}$ & & 79 & की & 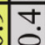 & ? & $\because$ & 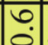 & ? & ? & $n$ & बेद & a. & & 움. \\
\hline BmKaTx16 & & & & & & & & & & & & & & & & & $?$ & ? & & 2 & $8^{\infty}$ & $\begin{array}{l}\infty \\
0 \\
\end{array}$ & $?$ & ?ִ & $\because$ & ?! & ¿ & $?$ & $\begin{array}{l}0 \\
0\end{array}$ & 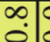 & $a$ & & 움 \\
\hline BmKM1 & & & & & & & & & & & & & & & 8 & & ? & $?$ & & 9 & $8 \stackrel{\infty}{0}$ & $\begin{array}{l}\infty \\
0\end{array}$ & $?$ & ?? & $n$ & $\because$ & ¿. & ?! & $\begin{array}{l}0 \\
0\end{array}$ & $\infty$ & $\infty$ & & 움 \\
\hline MeuNaTxa-13 & & & & & & & & & & & & & & 官 & E. & & ?! & $=$ & & 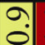 & & $\stackrel{\infty}{\infty}$ & 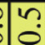 & : & $n$ & | & n? & ? & $n: 0$ & $\infty$ & $\infty$ & & ? \\
\hline MeuNaTxa-4 & & & & & & & & & & & & & & $\infty$ & $\infty$ & & : & $?$ & ? & ? & $\exists$ & ?. & 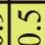 & : & | & | & - & : & n:0 & $\infty$ & a. & & $=$ \\
\hline MeuNaTxa-10 & & & & & & & & & & & & 8 & & $\infty$ & वे & & 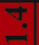 & $?$ & ب. & 2 & 0 & 9 & $\tilde{0}$ & : & | & | & ? & $?$ & n:0 & \begin{tabular}{l|c} 
\\
0 \\
0 & \\
\end{tabular} & a. & & - \\
\hline MeuNaTxa-8 & & & & & & & & & & & 8 & 8 & & $\hat{0}$ & $\begin{array}{l}\infty \\
0 \\
0\end{array}$ & & 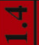 & ? & $?$ & $=$ & 웅 & $\infty$ & $\tilde{0}$ & 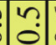 & \begin{tabular}{|l|}
0 \\
0 \\
0
\end{tabular} & 吕 & 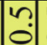 & $?$ & $\because$ & $\begin{array}{lll}\infty & \\
0 & & \\
0 & & \end{array}$ & $\infty$ & & = \\
\hline MeuNaTxa-11 & & & & & & & & & & 8 & 8 & 8 & & $\infty$ & वे. & & ? & $?$ & $\stackrel{0}{-}$ & ? & 욤 & $\infty$ & $\tilde{0}$ & 苗 & | & $\hat{0}$ & | & | & $\because$ & $\dot{0} \dot{0}^{2}$ & $a$ & & I \\
\hline MeuNaTxa-6 & & & & & & & & & 8 & 8 & 8 & 8 & & $\begin{array}{l}\infty \\
0 \\
0\end{array}$ & 9 & & 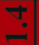 & $\because$ & $\stackrel{0}{-1}$ & $\cong$ & $=$ & $\hat{0}$ & $\because$ & $\begin{array}{l}0 \\
0 \\
0\end{array}$ & | & 10. & | & | & $\begin{array}{llc}n & 0 \\
0 & 0 & \end{array}$ & 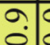 & 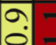 & & \\
\hline MeuNaTxa-5 & & & & & & & & 8 & 8 & 8 & 8 & 8 & & $\begin{array}{l}\infty \\
0 \\
0\end{array}$ & $\begin{array}{l}\infty \\
0 \\
0\end{array}$ & & ¿ & $?$ & ?? & I & $=$ & $\hat{0}$ & 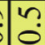 & $\begin{array}{l}0 \\
0 \\
0\end{array}$ & 吕 & 官 & - & 官 & $\begin{array}{lll}n & 0 \\
0 & 0 & 0\end{array}$ & \begin{tabular}{l|c}
$\infty$ & \\
0 & 0 \\
0
\end{tabular} & a. & & - \\
\hline MeuNaTxa-3 & & & & & & & & $?$ & $\stackrel{?}{?}$ & $\Xi$ & 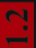 & ? & 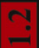 & فे. & a. & 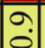 & 9 & : & 요. & aे & 9 & $?$ & 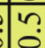 & : & $n$ & $n$ & ¿. & ث. & 寸.0 & $\begin{array}{l}\infty \\
0 \\
0\end{array}$ & ?. & & n? \\
\hline BmKaTx12 & & & & & & \begin{tabular}{l|l}
$\infty$ \\
0 \\
\end{tabular} & & : & Tे: & 0. & $\tilde{0}$ & 10 & $\begin{array}{ll}\infty \\
0 \\
0\end{array}$ & (0) & ○’ & 它 & i. & |' & 0. & $\infty$ & \begin{tabular}{|l|l}
$\infty$ & \\
0 & 0 \\
0
\end{tabular} & $0 ?$ & : & ? & $\tilde{0}$ & $\begin{array}{l}n \\
0 \\
0\end{array}$ & â & $\because$ & $\begin{array}{l}+0 \\
0\end{array}$ & $\begin{array}{l}\infty \\
0 \\
0\end{array}$ & 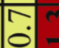 & & ? \\
\hline BmKTb-1 & & & & & ?! & बें & $\begin{array}{l}\infty \\
\infty \\
\dot{0}\end{array}$ & $\begin{array}{l}\infty \\
\infty \\
0\end{array}$ & \begin{tabular}{|l|} 
\\
\\
0
\end{tabular} & - & $\begin{array}{l}\infty \\
0 \\
0\end{array}$ & $\begin{array}{l}\infty \\
0 \\
0\end{array}$ & aे & $\begin{array}{l}\infty \\
0 \\
0\end{array}$ & $\tilde{0}$ & $\hat{0}$ & $\begin{array}{l}\infty \\
0 \\
0\end{array}$ & 范 & $\begin{array}{l}\infty \\
0 \\
0\end{array}$ & aे & aे & $0^{\circ}$ & ? & $\mid \begin{array}{l}0 \\
0 \\
0\end{array}$ & \begin{tabular}{|l|}
0 \\
\\
\end{tabular} & $\begin{array}{l}0 \\
0 \\
0\end{array}$ & : & $\tilde{c}$ & ñ: & $\begin{array}{ll}\infty & 0 \\
0 \\
0\end{array}$ & 文 & & IV: \\
\hline BmKTb & & & & 8 & ?ִ & ब.|c & $\begin{array}{l}\infty \\
0 \\
0\end{array}$ & $\begin{array}{l}\infty \\
0 \\
0\end{array}$ & \begin{tabular}{|l|}
$\infty$ \\
$\infty$ \\
0
\end{tabular} & - & 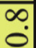 & $\begin{array}{c}\infty \\
0 \\
0\end{array}$ & 옴 & $\hat{0}$ & $\overrightarrow{0}$ & . & $\begin{array}{l}\infty \\
0 \\
0\end{array}$ & : & क्. & aे & बें & : & $?$ & : & ? & : & ?: & $\because$ & ?ी: & $\begin{array}{l}\infty \\
0 \\
0\end{array}$ & $\infty$ & & 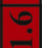 \\
\hline MkTx-3 & & & 요 & & 0 & .ं. & 0 & 0 & 이. & 임 & $\stackrel{0}{0}$ & 웅 & $\dot{0}$ & | & ف. & \begin{tabular}{|l|}
$\infty$ \\
0 \\
0
\end{tabular} & हे. & $\infty$ & वे. & \begin{tabular}{|l|l|}
$\infty$ & \\
0 & \\
\end{tabular} & \begin{tabular}{l|l}
$\infty$ & 1 \\
0 & 0
\end{tabular} & : & $\stackrel{0}{\circ}$ & : & 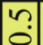 & $\begin{array}{l}n \\
0\end{array}$ & ? & ثे & $\because$ & \begin{tabular}{l|c}
$\infty$ & \\
0 & 0
\end{tabular} & $\begin{array}{l}\infty \\
0 \\
0\end{array}$ & $\begin{array}{ll}0 \\
0 \\
0\end{array}$ & \begin{tabular}{|l|} 
\\
0 \\
0
\end{tabular} \\
\hline MkTx-2 & & & & & 0 & $\begin{array}{l}\infty \\
0 .\end{array}$ & & & $\rightarrow$ & -1 & ?! & & 웅 & aे. & 9. & 임 & $\begin{array}{l}\infty \\
0 \\
\end{array}$ & 움 & & 웅. & 0 & :0. & $\stackrel{0}{8}$ & : & $n$ & $\begin{array}{l}0 \\
0 \\
0\end{array}$ & वे. & +⿱宀㠯:㔾 & 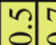 & : & त्: & : & $\hat{0}$ \\
\hline & $\frac{⿱ 亠 凶}{\Sigma}$ & $\begin{array}{l}\frac{m}{x} \\
\frac{x}{2} \\
\frac{x}{2}\end{array}$ & $\begin{array}{l}0 \\
\hat{E} \\
\bar{\emptyset} \\
0\end{array}$ & 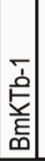 & 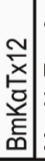 & 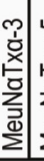 & 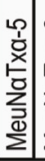 & \begin{tabular}{l|}
0 \\
0 \\
0 \\
0 \\
0 \\
$\vdots$ \\
$\vdots$ \\
$\sum$ \\
$\Sigma$
\end{tabular} & 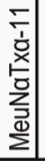 & 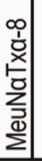 & 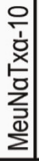 & 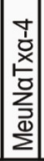 & 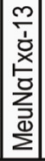 & $\frac{\sum}{\sum}$ & 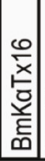 & 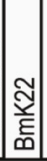 & 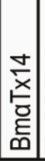 & 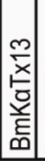 & 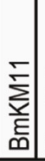 & 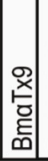 & 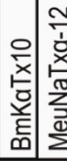 & 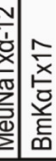 & 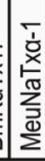 & 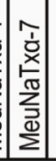 & 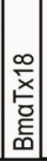 & $\begin{array}{l}\text { 궁 } \\
\text { हे } \\
\text { है }\end{array}$ & $\mid$ & \begin{tabular}{|l} 
\\
$\overline{\mathbf{z}}$ \\
흠
\end{tabular} & 흘 & 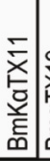 & 焉 & 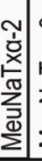 & 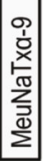 \\
\hline
\end{tabular}

FIG. 10. Pairwise $\omega$ estimation of Mesobuthus $\boldsymbol{\alpha}$-toxins. The $\omega$ values, estimated by the method of Nei and Gojobori (28) implemented in CODEML (29), are shadowed in different colors: $\omega<0.5$ (gray); $0.5 \leq \omega \leq 1$ (yellow); $1<\omega<10$ (red); $\infty$ (blue).

MeuNaTx $\alpha-2$ (as an example) and found that $1 \mu \mathrm{m}$ accelerates the recovery from fast inactivation in $\mathrm{Na}_{\mathrm{v}} 1.4$ and $\mathrm{DmNa}_{\mathrm{v}} 1$ (Fig. 9).

Positive Selection in Mesobuthus $\alpha$-Toxins-To study whether positive selection has driven adaptive substitutions of $\alpha$-toxins in the Mesobutus lineage, we first analyze all currently available toxin sequences from two sibling species (M. eupeus and M. martensii) (Fig. 3). Nucleotide sequence alignment was first used for pairwise analysis to calculate $\omega$ values between two toxins. Overall, the majority of the $\omega$ 
TABLE IV

Maximum likelihood estimates of parameters and sites inferred to be under positive selection for $\alpha$-toxins in the Mesobuthus lineage. $S$ represents tree length; $p$ is the number of parameters in the $\omega$ distribution; I is the log likelihood; $\kappa$ is transition/transversion rate ratio. Twice

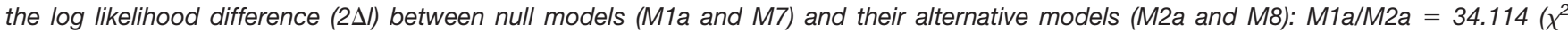
significant value: $p<0.001) ; M 7 / M 8=39.502(p<0.001)$. Positively selected sites identified by the Bayes Empirical Bayes (BEB) and Naive Empirical Bayes (NEB) methods under M2a and M8 with $P$ (posterior probabilities) $\geq 0.99$ are indicated by ** and $\geq 0.95$ by *. Residues are numbered according to MeuNaTx $\alpha-1$. Two $\omega$ values in models M2a and M8 as indicators of positive selection are boldfaced

\begin{tabular}{|c|c|c|c|c|c|c|}
\hline Model & $S$ & $p$ & l & $\kappa$ & $\begin{array}{l}\text { Estimates of } \\
\text { parameters }\end{array}$ & Positively selected sites \\
\hline M0 (one-ratio) & 5.71 & 1 & -1812.815 & 1.357 & $\omega=0.906$ & None \\
\hline M1a (neutral) & 6.28 & 2 & -1733.642 & 1.228 & $\begin{array}{l}p_{0}=0.490\left(p_{1}=0.510\right) \\
\omega_{0}=0.076\left(\omega_{1}=1\right)\end{array}$ & Not allowed \\
\hline M2a (selection) & 6.70 & 4 & -1716.585 & 1.420 & $\begin{array}{l}p_{0}=0.458 \\
p_{1}=0.358\left(p_{2}=0.184\right) \\
\omega_{0}=0.094\left(\omega_{1}=1\right) \\
\omega_{2}=\mathbf{2 . 9 4 0}\end{array}$ & $\begin{array}{l}8 \mathrm{D}, 9 \mathrm{D}^{\star \star}, 15 \mathrm{~F}^{\star \star}, 18 \mathrm{R}^{\star \star}, 20 \mathrm{~A}^{\star} \\
38 \mathrm{~W}^{\star \star}, 39 \mathrm{~A}^{\star \star}, 41 \mathrm{Q}, 50 \mathrm{~K}\end{array}$ \\
\hline M8 (beta\& $\omega)$ & 6.55 & 4 & -1718.859 & 1.440 & $\begin{array}{l}p_{0}=0.696\left(p_{1}=0.304\right) \\
p=0.364, q=0.606 \\
\omega_{\mathrm{s}}=\mathbf{2 . 6 4 5}\end{array}$ & $\begin{array}{l}8 D^{\star \star}, 9 D^{\star \star}, 15 F^{\star \star}, 18 R^{\star \star}, 20 A^{\star \star} \\
38 W^{\star \star}, 39 A^{\star \star}, 41 Q^{*}, 50 K^{\star}\end{array}$ \\
\hline
\end{tabular}

values observed are $>0.5$ and even some $>1$ (Fig. 10), which are significantly larger than those calculated from genes under neutral evolution (about 0.2) (42). Our observation thus indicates that Mesobuthus $\alpha$-scorpion toxins evolve in an accelerated manner. To pinpoint which sites suffering positive selection and to test whether the functionally important substitutions identified by site-directed mutagenesis reside at these sites, we employed maximum likelihood models of codon substitution where five models (M0, M1a, M2a, M7, and M8) were implemented to construct two likelihood ratio tests (M1a/M2a and M7/M8). The M0 assumes that all sites have a $\omega$ ratio of 0.906 , however, it fits the data worse than any other model. Two selection models (M2a and M8) do detect the presence of a substantial proportion (0.2-0.3) of PSSs in Mesobuthus $\alpha$-scorpion toxins with a similar $\omega$

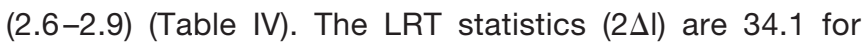
$\mathrm{M} 1 \mathrm{a} / \mathrm{M} 2 \mathrm{a}$ and 39.5 for M7/M8, which both are much greater than the $\chi^{2}$ distribution critical values $(p<0.001)$, indicating the existence of positive selection in Mesobuthus $\alpha$-toxins. Furthermore, M2a and M8 both convergently detected nine identical PSSs (8, 9, 15, 18, 20, 38, 39, 41, and 50) (Fig. 1; Table IV), of which sites 8 and 9 are located on the aminoterminal five-residue-turn; sites 15 and 18 preceding the $\alpha$-helix; site 20 on the $\alpha$-helix; sites 38 and 39 on the end of the second $\beta$-strand; site 41 on the $\beta$-turn linking the second and third $\beta$-strands; site 50 on the end of the last $\beta$-strand. When locating these PSS residues on the threedimensional (3D) structure, we found that most of them spatially cluster on one face of the toxin molecule despite these sites are not contiguous in the primary sequence (Fig. 11). The only exception is site 50 that appears in the opposite of the surface. Functional significance of these PSSs will be discussed below.

\section{DISCUSSION}

MeuNaTxas Are New VGSC Ligands-So far, about sixty $\alpha$-toxins have been isolated or cloned from scorpions (13), however, little information is available with regard to their selectivity toward specific VGSCs due to the lack of a complete subtype targets for testing. BmKM1 and OD1 are two examples tested for multiple channel isoforms, the former active on $\mathrm{Na}_{v} 1.2,1.3,1.5,1.6$, and $\mathrm{DmNa}_{v} 1(32,43)$, and the latter affecting $\mathrm{Na}_{\mathrm{v}} 1.3,1.5,1.7$, and $\mathrm{DmNa}_{\mathrm{v}} 1(44,45)$. These two toxins were found to bind to the channels with differential affinities. To the best of our knowledge, the work presented here represents the first report that systemically evaluated the effects of four paralogous $\alpha$-toxins on eight VGSCs, including seven mammalian isoforms and the Drosophila counterpart $\mathrm{DmNa}_{v} 1$. The differential selectivity of these toxins on different channel subtypes renders them useful for identification of the channels at various tissues and act as molecular probes for studying structure-function relationships of site 3 of the sensitive VGSCs. In this regard, MeuNaTx $\alpha-2$ and MeuNaTx $\alpha-4$ are of particular interest due to their high selectivity. MeuNaTx $\alpha-2$ specifically inhibits the inactivation process of $\mathrm{Na}_{\mathrm{v}} 1.4$ that is the only one VGSC subtype expressed in skeletal muscles, whereas MeuNaTx $\alpha-4$ shows a prospect in developing a new pest control agent because of its selective on $\mathrm{DmNa}_{\mathrm{v}} 1$ and its killing activity on insects. Among all scorpion $\alpha$-toxins previously identified, Lqh $\alpha$ IT from Leiurus quinquestriatus is considered as the best candidate for developing an agent for pest control because of its strong insecticidal activity (46). However, this has been challenged by its absence of selectivity on mammalian VGSCs. Unlike Lqh $\alpha$ IT that only shows about 80 -fold selectivity for $\mathrm{DmNa}_{\mathrm{v}} 1$ over $\mathrm{rNa}_{\mathrm{v}} 1.4$ (47), MeuNaTx $\alpha-4$ shows more than 15385fold selectivity for $\mathrm{DmNa}_{\mathrm{v}} 1$ over seven mammalian VGSCs $\left(\mathrm{Na}_{\mathrm{v}} 1.2-\mathrm{Na}_{\mathrm{v}} 1.8\right)$. 
A

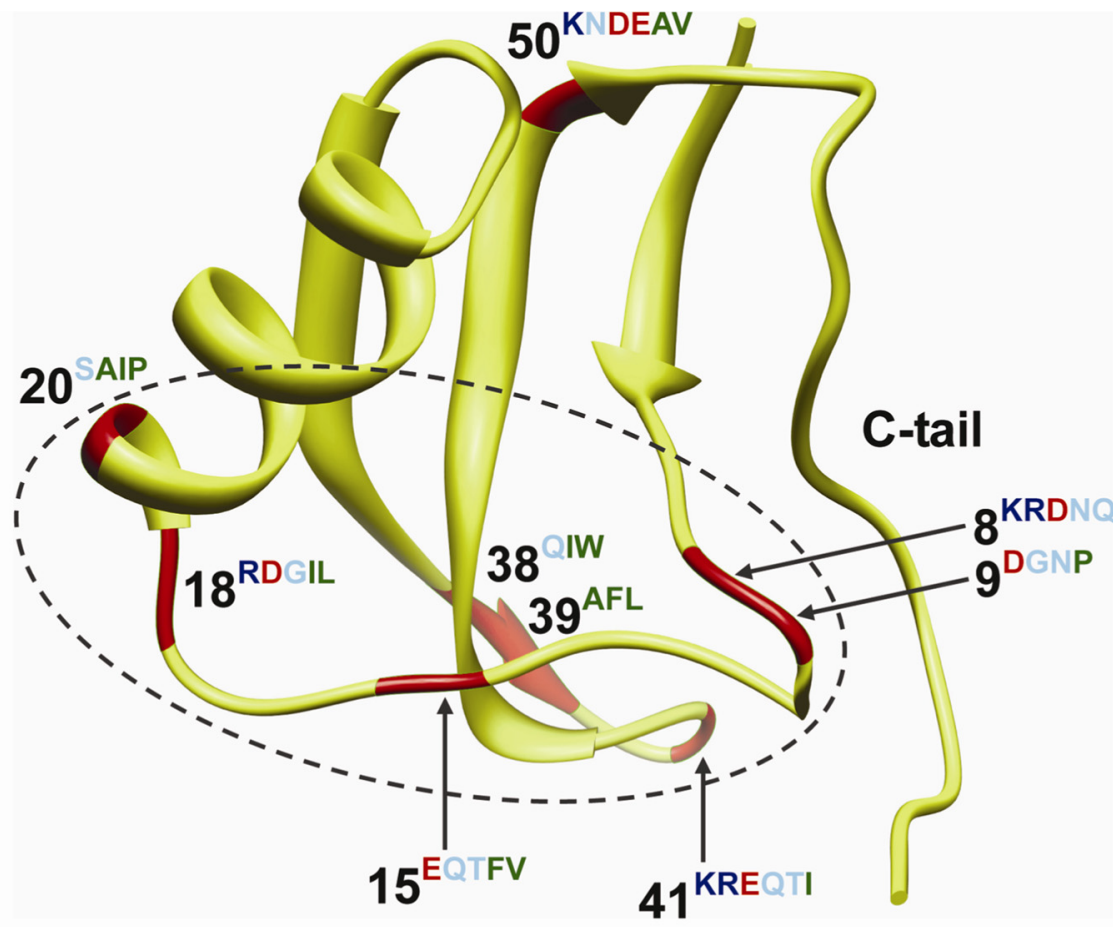

B

\begin{tabular}{|c|c|c|c|c|c|}
\hline \multirow[t]{2}{*}{ B } & $\beta 1$ & \multicolumn{2}{|c|}{$N T$} & & \\
\hline & 1234 & 7890 & 11111 & & \\
\hline BmKM1 & VRDA & $\mathrm{AKPH}$ & $\mathrm{CVY}$ & $\mathrm{EC}$ & $A B$ \\
\hline \multicolumn{6}{|l|}{ FS } \\
\hline BmKM1 & 000 & 000 & & & \\
\hline Lqh3 & & & & 0 & ০০ \\
\hline LqhaIT & 0 & 00 & 0 & & oo \\
\hline Lqh2 & 0 & & & o & \\
\hline
\end{tabular}

$\alpha$-helix

$\overbrace{R 2}^{\beta T} \quad \beta 3 \quad \beta T \quad C$-tail

11222222222233333333334444444444555555555566666

BmKM1 VRDAYIAKPHNCVYECARNEYCNDLCTKNGAKSGYCQWVGKYGNGCWCIELPDNVPIRVPGKCH

FS

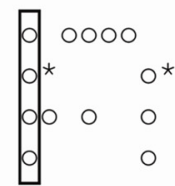

○

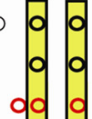

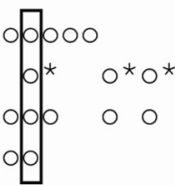

O

2010

This work

$\begin{array}{ccc}0 & 0 \\ 0 & 0 & 0 \\ 0 & 0\end{array}$

FIG. 11. Structural and functional features of PSSs in Mesobuthus $\alpha$-toxins. A, Mapping of the PSSs on the crystal structure of BmK M1 (pdb entry 1SN1), where PSSs are in shown in red. Different amino acid types in PSSs are highlighted in color: blue, positively charged; red, negatively charged; cyan, polar; green, hydrophobic; $B$, Comparison of functional sites (FSs) of four well-identified $\alpha$-toxins and PSSs estimated from different sequence sources [2004 (52); 2010 (47)]. $\beta$ T: $\beta$-turn; NT: N-terminal five-residue turn; "o" represents positions of FSs or PSSs. PSSs commonly predicted in three different studies are shadowed in yellow and PSSs reported here associated with functions are shown in red. "residue numberings in Lqh3 are 39, 45, 59, 64, and 66, respectively. Identical FSs or PSSs are boxed.

Possible Roles of Positive Selection Sites in Functional Diversification of Mesobuthus $\alpha$-Toxins-Identifying individual codons of a gene family that undergoes advantageous substitutions is evidence for adaptive evolution which frequently occurs in proteins implicated in evolutionary arms race (48). Some such examples include the major histocompatibility complex (MHC) (49), the retroviral inhibitor TRIM5 $\alpha$ in primates $(50)$, neurotoxins from cone snails and scorpions $(51,52)$, sperm lysin (53), and testes-specific $\alpha 4$ proteasome subunit in Drosophila (54). As an important toxic component, scorpion $\alpha$-toxins constitute the target of positive selection for adapting to evolutionary alteration of VGSCs in the course of scorpion and its prey interaction. Thus this class of toxins has become a focus of research in evolutionary biology. Thanks to extensive site-directed mutagenesis of four $\alpha$-toxins (BmKM1, Lqh3, Lqh $\alpha$ IT, and Lqh2) from different functional subgroups $(32,36,37,55-57)$, we can now draw structural or functional significance of these PSSs. As shown in Fig. 11, despite overall there are two clear functional domains comprising NC-domain and Core-domain in Lqh $\alpha$ IT and BmKM1, they 
A

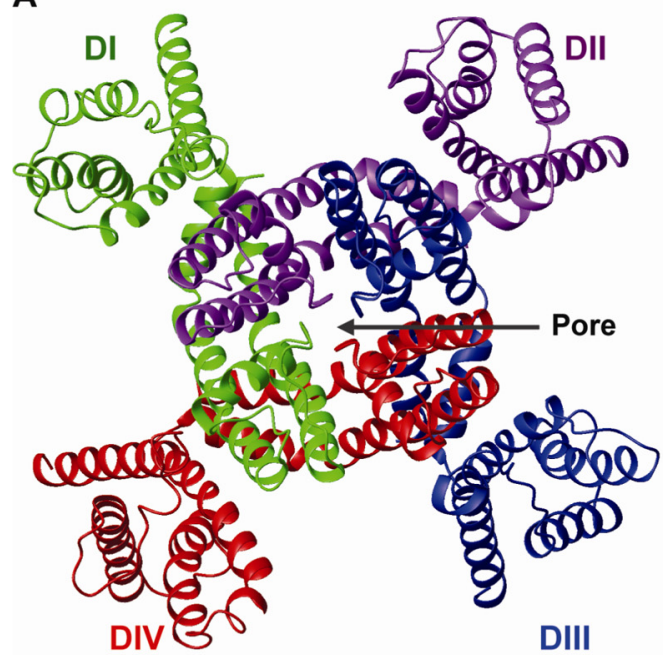

B

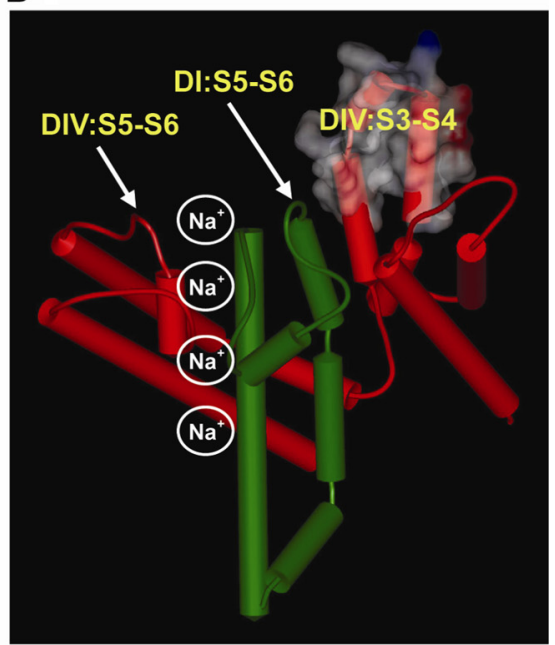

C

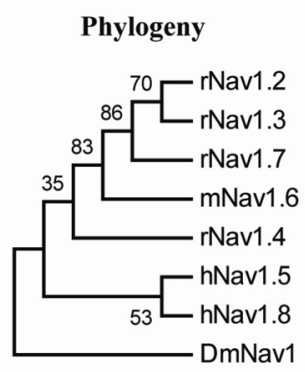

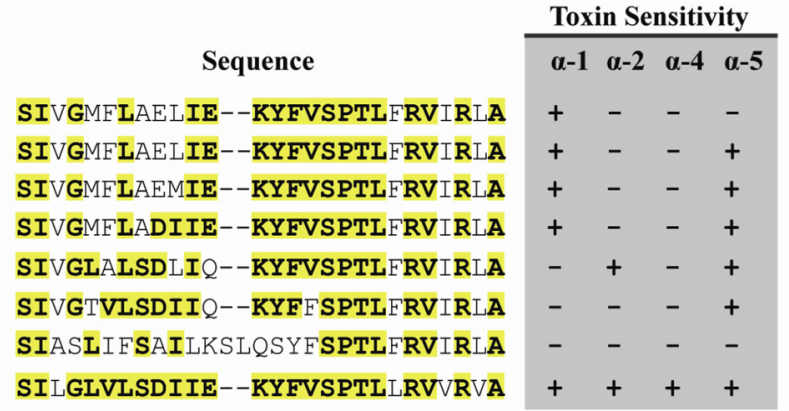

$\alpha-1 \quad \alpha-2 \quad \alpha-4 \quad \alpha-5$

FIG. 12. Molecular basis for channel subtype selectivity of MeuNaTx $\alpha$ s. $A$, The model structure of DI-DIV domains of DmNa 1 . All the four domains, shown in different colors (DI, green; DII, purple; DIII, blue; DIV, red), were build by Homer, a comparative modeling server (http://protein.cribi.unipd.it/homer/) and the atomic structure of a mammalian chimeric VGPC (pdb entry 2R9R) was used as template. Domain assembly was performed by Swiss PDB Viewer (http://spdbv.vital-it.ch/); $B$, Structural representation of the DmNa 1 site 3 comprising three

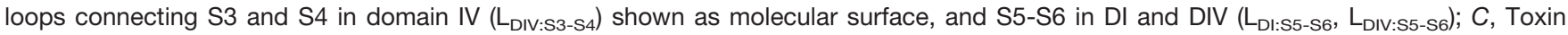
sensitivity of different VGSCs associated with sequences in $\mathrm{L}_{\mathrm{DIV}: \mathrm{S} 3-\mathrm{S} 4} \cdot \alpha$ : MeuNaTx $\alpha$. Identical amino acids to DmNa 1 are shadowed in yellow. The phylogeny was reconstructed based on the sequence of site 3 listed here. Bootstrap values are shown at nodes. +, activity; -, no activity.

both only share eight identical functional sites $(2,8,10,38,41$, 57,58 , and 59). Moreover, the functionally important fiveresidue turn region in Lqh $\alpha \mathrm{IT}$ and BmKM1 are excluded in the functional surfaces of Lqh2 and Lqh3. These observations suggest that sites composed of functional surfaces may differ among toxins, consistent with the proposal that all $\alpha$-toxins bind to a partially overlapping region within site 3 of VGSCs by a similar but nonidentical functional surface located on their exteriors.

In our early work (52), we analyzed $\alpha$-toxins from four different scorpion species (M. martensii, Androctonus australis, L. quinquestriatus, and Buthus occitanus) by using the maximum likelihood models of codon substitution that detected seven PSSs $(10,17,18,37,39,41$, and 56$)$, in which 10,17 , and 18 were found in the functional regions of $\alpha$-toxins (36). Subsequently, Weinberger et al. used the same method to analyze sequences from more scorpion species and identified four PSSs $(10,18,39$, and 41) identical to those mentioned above and confirmed functional roles of 39 and 41 by mutagenesis experiments (47). Based on a complete data from two Mesobuthus species, we identified a total of nine PSSs $(8,9,15,18,20,38,39,41$, and 50$)$ by the same method, which include three functional sites $(18,39$, and 41$)$ common to those predicted previously $(47,52)$ (Fig. 11B). Of nine PSSs derived from the Mesobuthus lineage seven were found in the functional surface of toxins. It is striking that all these sites are located on three structurally variable and functionally important regions $(36,47,58)$, in which two (residues 8-12 and 37-43) are associated with phylogenetic preference of $\alpha$-toxins, and one (residues 18-21) are implicated in the receptor binding. Our analysis identified six new PSSs, in which five $(8,9,15,38$, and 50$)$ fall into the functional region. The first finding that sites 8 and 9 undergoing positive selection is of particular interest because in Lqh $\alpha \mathrm{IT}$, these two sites were found to be directly involved in binding to the loop connecting S3-S4 of DIV (abbreviated as L LIV:S3-S4) (59) whereas in BmKM1, the residue couplet $(8,9)$ has been proposed to act as a molecular switch where the substitution at site 8 with specific residue can redirect the $\alpha$-like characteristics of BmKM1 to either insect or much higher specificity to 
mammalian VGSCs, whereas P9N becomes highly specific for mammals (60); Site 15 is a key determinant whose mutations profoundly affect affinities of Lqh2 and Lqh3 on mammalian rather than insect VGSCs $(37,57)$; Site 38 was also identified in the interface of Lqh $\alpha$ IT and $\mathrm{L}_{\text {DIV:S3-34 }}$ of $\mathrm{DmNa}_{\mathrm{v}} 1$ (59) and its functional importance has been revealed in all the four toxins $(32,36,37,55-57)$ (Fig. 11). Although functional importance of site 50 has not been experimentally evaluated so far, it is highlighted by two natural mutants (MeuNaTx $\alpha-4$ and MeuNaTx $\alpha-5$ ) where the mutation V50A results in activity on multiple mammalian VGSC subtypes. This suggests a switch role of this site in discriminating between mammalian and insect VGSCs. These observations support the importance of these new PSSs in the divergence of Mesobuthus toxins and thus these amino acid sites constitute good starting points in evolution-guided design of novel VGSC-targeted molecules with improved potency and phylogenetic selectivity.

Molecular Basis for Channel Subtype Selectivity of MeuNaTx $\alpha$ s-It is shown that scorpion $\alpha$-toxins exhibit phylogenetic preference and differential affinity toward different VGSCs. Such functional divergence is associated with mutations in bioactive surfaces on the toxins and with variations in site 3 of VGSCs (18). Extensive studies suggest that three extracellular loops comprise site 3 . These loops include $L_{\text {DIV:S3-S4, }} L_{\text {DI:S5-S6, }}$ and $L_{\text {DIV:S5-S6. To observe the locations }}$ of these three loops on the channel, we reconstructed a model structure of $\mathrm{DmNa}_{\mathrm{v}} 1$, in which $\mathrm{L}_{\mathrm{DI} \text { :S5-S6 }}$ was found to be located between $\mathrm{L}_{\text {DIV:S5-S6 }}$ and $\mathrm{L}_{\text {DIV:S3-S4, making these }}$ three loops form a contiguous region (Fig. 12A and 12B) for toxin binding. Among these three loops, $\mathrm{L}_{\mathrm{DIV}: \mathrm{S3}-\mathrm{S} 4}$ is considered as the most important region because some mutations (e.g. Glu ${ }^{1613}$, Lys ${ }^{1617}$, and Pro ${ }^{1622}$ ) in it can cause significant effects on binding of scorpion $\alpha$-toxin (LqTx) or sea anemone (ATX II) on $r \mathrm{Na}_{\mathrm{v}}$ 1.2. Moreover, recent NMR analysis identified an interface between Lqh $\alpha$ IT and $\mathrm{L}_{\text {DIV:S3-S4 }}$ of $\mathrm{DmNa}_{\mathrm{v}} 1$, in which a functional surface of the toxin comprising Lys ${ }^{8}, \mathrm{Asn}^{9}$, $\mathrm{Cys}^{12}, \mathrm{Val}^{13}, \mathrm{Arg}^{18}$, and $\operatorname{Trp}^{38}$ is involved (59). Of these functional residues, three $(8,9$, and 18$)$ have been identified here as PSSs, suggesting that this loop constitutes a critical driving force for the adaptive evolution of Mesobuthus $\alpha$-scorpion toxins. To elucidate which residues of the loop of various VGSCs are possibly implicated in interacting with MeuNaTx $\alpha$ s, we compared the amino acid sequences of $L_{\text {DIV: }}$ s3-s4 of all VGSCs used in this study and their pharmacological sensitivity pattern to these toxins (Fig. 12C). We found that an acidic residue at position 1616 (Glu ${ }^{1616}$, all positions of VGSCs described here numbered according to $\left.\mathrm{rNa}_{\mathrm{v}}{ }_{1.2}\right)$ is shared by five sensitive VGSCs $\left(\mathrm{rNa}_{\mathrm{v}} 1.2, \mathrm{rNa}_{\mathrm{v}} 1.3, \mathrm{mNa}_{\mathrm{v}} 1.6\right.$, $\mathrm{rNa}_{\mathrm{v}} 1.7$, and $\mathrm{DmNa}_{\mathrm{v}} 1$ ) to MeuNaTx $\alpha-1$. In the resistant channels, this position is occupied by $\mathrm{Gln}^{1616}$ in $\mathrm{rNa}_{\mathrm{v}} 1.4$ and $\mathrm{hNa}_{\mathrm{v}} 1.5$ or Lys ${ }^{1616}$ in $\mathrm{rNa}_{\mathrm{v}} 1.8$. $\mathrm{DmNa}_{\mathrm{v}} 1$ is the only target of MeuNaTx $\alpha-4$ and possesses four specific residues at positions Leu ${ }^{1607}$, Leu ${ }^{1625}$, Val ${ }^{1628}$, and Val ${ }^{1630}$, which all differ from those in the resistant channels. For MeuNaTx $\alpha-2$, the only mammalian VGSC target is $\mathrm{rNa}_{\mathrm{v}} 1.4$ that contains a specific residue at position $\mathrm{Ala}^{1610}$. For MeuNaTx $\alpha-5$, no sensitive channel-specific residues were recognized in $\mathrm{L}_{\mathrm{DIV}}$ :S3-S4, and in this region $\mathrm{rNa}_{\mathrm{v}} 1.2$ and $\mathrm{rNa}_{\mathrm{v}} 1.3$ have completely identical sequences, but their sensitivity on this toxin is different, suggesting that additional loops such as $\mathrm{L}_{\mathrm{DI}: \mathrm{S5}-\mathrm{S6}}$; $\mathrm{L}_{\mathrm{DIV} \text { :S5-S6 }}$ are possibly involved (6). The resistance of $\mathrm{hNa}_{\mathrm{v}} 1.8$ on all four MeuNaTx $\alpha$ s may be associated with its unique amino acid sequences, such as a two-amino acid (Ser-Leu) insertion; mutations at positions 1607-1608 (Ala-Ser in $\mathrm{hNa}_{\mathrm{v}} 1.8$ but Leu/Val-Gly in other subtypes and $\mathrm{DmNa}_{\mathrm{v}} 1$ ), 1611 (Phe in $\mathrm{hNa}_{\mathrm{v}} 1.8$ but Leu in other subtypes and $\mathrm{DmNa}_{\mathrm{v}} 1$ ), 1613 (Ala in $\mathrm{hNa}_{\mathrm{v}} 1.8$ but Asp or Glu in other subtypes and $\mathrm{DmNa}_{\mathrm{v}} 1$ ), 1617-1618 (Gln-Ser in hNa 1.8 but Lys-Tyr in other subtypes and $\mathrm{DmNa}_{\mathrm{v}} 1$ ). At these positions, several have been identified as key determinants for toxin binding. For example, the mutation from a Lys to a Thr at position 1617 (Lys1617Thr) was found to result in decreased affinity of the toxin on $\mathrm{Na}_{v} 1.7$ and Lys1617Ser in the scorpion VGSC is considered as a key mutation for the scorpion's adaptive insensitivity (61). In addition, Glu/Asp ${ }^{1613}$ has been verified to be the most determinant for toxin binding possibly through electrostatic interaction with a positively charged residue in the toxin $(6,7)$. In the sensitive VGSCs of MeuNaTx $\alpha-1$, Glu ${ }^{1616}$ could also participate in such electrostatic interaction because of its adjacent position to Glu/Asp ${ }^{1613}$. Further elucidation and comparison of bioactive surfaces of these four distinct $\alpha$-toxins could facilitate identification of key determinants that control specific binding of the toxins to phylogenetically distinct VGSCs. This will enable design of selective agents for pest control and disease treatment by regulating excitability of neurons, muscles, and heart (62).

Acknowledgments - We thank A. L. Goldin (University of California, Irvine, USA) for $\mathrm{rNa}_{\mathrm{v}}$ 1.2, $\mathrm{rNa}_{\mathrm{v}}$ 1.3, $\mathrm{mNa}_{\mathrm{v}}$ 1.6; G. Mandel (Stony Brook University, Stony Brook, NY) for $\mathrm{rNa}_{\mathrm{v}} 1.4$; R.G. Kallen (Univ. of Pennsylvania, Philadelphia, USA) for $\mathrm{hNa}_{\mathrm{v}} 1.5$. A. George, Jr. (Vanderbilt University, Nashville, TN) for $\mathrm{hNa}_{\mathrm{v}} 1.5$; P. Dietrich (Roche Applied Science) for $\mathrm{rNa}_{\mathrm{v}} 1.7$ and $\mathrm{hNa} v 1.8$; L. Isom (University of Michigan, Ann Arbor); S. H. Heinemann (Friedrich-Schiller-Universität, Jena, Germany) for $r \beta 1$; S. C. Cannon (University of Texas, Dallas) for $h \beta 1$; and M.S. Williamson (IACR-Rothamsted, Harpenden, UK) for $\mathrm{DmNa}_{\mathrm{v}} 1$ and tipE. We also thank X. Qu (Institute of Zoology, CAS, Beijing, China) for providing Musca domestica TJS and Musca domestica BJD for quantitative evaluation of MeuNaTx $\alpha-4$ insect toxicity.

* This work was supported by grants from The National Natural Science Foundation of China (30730015 and 30921006) to S.Z.; The National Basic Research Program of China (2010CB945300) to S.Z.; Bilateral Cooperation for the 16th Session of the Sino-Belgian S\&T Mixed Commission to S.Z.; and G.0330.06 and G.0257.08 (F.W.O.Vlaanderen), OT-05-64 (K.U.Leuven), P6/31 (Interuniversity attraction Poles Program- Belgian State- Belgian Science Policy) and BIL 07/10 (China) to J.T.

S This article contains supplemental Figs. S1 and S2 and Tables S1 to S4 and Appendix.

** These authors contributed equally to this work.

The authors have declared no conflicts of interest. 
Authors' contributions to this work: S.Z. designed the research; B.G. and S.Z. performed molecular cloning, peptide isolation and characterization, and insect toxicity assays; S.P. and J.T. performed electrophysiological experiments; X.L. and C.C. determined the NMR structure of MeuNaTx $\alpha-5$; S.Z. performed evolutionary analysis and comparative modeling; S.Z., C.C. and J.T. wrote the paper.

\| To whom correspondence should be addressed: Group of Animal Innate Immunity, State Key Laboratory of Integrated Management of Pest Insects and Rodents, Institute of Zoology, Chinese Academy of Sciences, 1 Beichen West Road, Chaoyang District, Beijing 100101, China. E-mail: Zhusy@ioz.ac.cn.

$\S \S$ These authors contributed equally to this work.

\section{REFERENCES}

1. Rochat, H., and Martin-Eauclaire, M. F. (2000) Animal Toxins: Facts and Protocols. Birkhauser Verlag, Basel, Boston, Berlin

2. Billen, B., Bosmans, F., and Tytgat, J. (2008) Animal peptides targeting voltage-activated sodium channels. Curr. Pharm. Design. 14, 2492-2502

3. Lewis, R. J., and Garcia, M. L. (2003) Therapeutic potential of venom peptides. Nat. Rev. Drug Discov. 2, 790-802

4. Catterall, W. A. (1995) Structure and function of voltage-gated ion channels. Annu. Rev. Biochem. 64, 493-531

5. Catterall, W. A. (2000) From ionic currents to molecular mechanisms: The structure and function of voltage-gated sodium channels. Neuron 26, 13-25

6. Catterall, W. A., Cestèle, S., Yarov-Yarovoy, V., Yu, F. H., Konoki, K., and Scheuer, T. (2007) Voltage-gated ion channels and gating modifier toxins. Toxicon 49, 124-141

7. Cestèle, S., and Catterall, W. A. (2000) Molecular mechanisms of neurotoxin action on voltage-gated sodium channels. Biochimie 82, 883-892

8. Geffeney, S., Brodie E. D., Jr., Ruben, P. C., and Brodie, E. D., 3rd (2002) Mechanisms of adaptation in a predator-prey arms race: TTX-resistant sodium channels. Science 297, 1336-1339

9. Geffeney, S. L., Fujimoto, E., Brodie, E. D., 3rd Brodie, E. D., Jr, and Ruben, P. C. (2005) Evolutionary diversification of TTX-resistant sodium channels in a predator-prey interaction. Nature 434, 759-763

10. Dib-Hajj, S. D., Black, J. A., and Waxman, S. G. (2009) Voltage-gated sodium channels: therapeutic targets for pain. Pain Med. 10, 1260-1269

11. Tate, S., Benn, S., Hick, C., Trezise, D., John, V., Mannion, R. J., Costigan, M., Plumpton, C., Grose, D., Gladwell, Z., Kendall, G., Dale, K., Bountra, C., and Woolf, C. J. (1998) Two sodium channels contribute to the TTX-R sodium current in primary sensory neurons. Nat. Neurosci. 1, 653-655

12. Possani, L. D., Becerril, B., Delepierre, M., and Tytgat, J. (1999) Scorpion toxins specific for $\mathrm{Na}^{+}$-channels. Eur. J. Biochem. 264, 287-300

13. Rodriguez de la Vega, R. C., and Possani, L. D. (2005) Overview of scorpion toxins specific for $\mathrm{Na}^{+}$channels and related peptides: biodiversity, structure-function relationships and evolution. Toxicon 46, 831-844

14. Bosmans, F., and Tytgat, J. (2007) Voltage-gated sodium channel modulation by scorpion alpha-toxins. Toxicon $49,142-158$

15. Zhu, S., Gao, B., and Tytgat, J. (2005) Phylogenetic distribution, functional epitopes and evolution of the CS $\alpha \beta$ superfamily. Cell. Mol. Life Sci. 62, 2257-2269

16. Jover, E., Couraud, F., and Rochat, H. (1980) Two types of scorpion neurotoxins characterized by their binding to two separate receptor sites on rat brain synaptosomes. Biochem. Biophys. Res. Comm. 95, 1607-1614

17. Wheeler, K. P., Watt, D. D., and Lazdunski, M. (1983) Classification of $\mathrm{Na}$ channel receptors specific for various scorpion toxins. Pflügers Archiv. 397:164-165

18. Gordon, D., Karbat, I., Ilan, N., Cohen, L., Kahn, R., Gilles, N., Dong, K., Stühmer, W., Tytgat, J., and Gurevitz, M. (2007) The differential preference of scorpion $\alpha$-toxins for insect or mammalian sodium channels: Implications for improved insect control. Toxicon. 49, 452-472

19. Schiavon, E., Sacco, T., Cassulini, R. R., Gurrola, G., Tempia, F., Possani, L. D., and Wanke, E. (2006) Resurgent current and voltage sensor trapping enhanced activation by a beta-scorpion toxin solely in Nav1.6 channel. Significance in mice Purkinje neurons. J. Biol. Chem. 281, 20326-20337

20. Gurevitz, M., Karbat, I., Cohen, L., Ilan, N., Kahn, R., Turkov, M., Stankiewicz, M., Stühmer, W., Dong, K., and Gordon, D. (2007) The insecticidal potential of scorpion $\beta$-toxins. Toxicon $49,473-489$

21. Goudet, C., Huys, I., Clynen, E., Schoofs, L., Wang, D. C., Waelkens, E., and Tytgat, J. (2001) Electrophysiological characterization of BmK M1, an alpha-like toxin from Buthus martensi Karsch venom. FEBS Lett. 495, $61-65$

22. Zhu, S., and Gao, B. (2006) Molecular characterization of a possible progenitor sodium channel toxin from the Old World scorpion Mesobuthus martensii. FEBS Lett. 580, 5979-5987

23. Gao, B., Peigneur, S., Dalziel, J., Tytgat, J., and Zhu, S. (2011) Molecular divergence of two orthologous scorpion toxins affecting potassium channels. Comp. Biochem. Physiol. A Mol. Integr. Physiol. 159, 313-321

24. Wuthrich, K. (1986) NMR of proteins and nucleic acids, John Wiley \& Sons

25. Liman, E. R., Tytgat, J., and Hess, P. (1992) Subunit stochiometry of a mammalian $\mathrm{K}^{+}$channel determined by construction of multimeric cDNAs Neuron 9:861-871

26. Maggio, F., and King, G. F. (2002) Scanning mutagenesis of a Janus-faced atracotoxin reveals a bipartite surface patch that is essential for neurotoxic function. J. Biol. Chem. 277, 22806-22813

27. Qiu, X., Li, M., Luo, H., and Fu, T. (2007) Molecular analysis of resistance in a deltamethrin-resistant strain of Musca domestica from China. Pest. Biochem. Physiol. 89, 146-150

28. Nei, M., and Gojobori, T. (1986) Simple methods for estimating the numbers of synonymous and nonsynonymous nucleotide substitutions. Mol. Biol. Evol. 3, 418-426

29. Yang, Z. (2007) PAML 4: Phylogenetic Analysis by Maximum Likelihood. Mol. Biol. Evol. 24, 1586-1591

30. Long, S. B., Tao, X., Campbell, E. B., and MacKinnon, R. (2007) Atomic structure of a voltage-dependent $\mathrm{K}^{+}$channel in a lipid membrane-like environment. Nature 450, 376-382

31. Bontems, F., Roumestand, C., Gilquin, B., Menez, A., and Toma, F. (1991) Refined structure of charybdotoxin: common motifs in scorpion toxins and insect defensins. Science 254, 1521-1523

32. Liu, L. H., Bosmans, F., Maertens, C., Zhu, R. H., Wang, D. C., and Tytgat, J. (2005) Molecular basis of the mammalian potency of the scorpion alpha-like toxin, BmK M1. FASEB J. 19, 594-596

33. Martin-Eauclaire, M. F., Céard, B., Ribeiro, A. M., Diniz, C. R., Rochat, H., and Bougis, P. E. (1994) Biochemical, pharmacological and genomic characterisation of Ts IV, an $\alpha$-toxin from the venom of the South American scorpion Tityus serrulatus. FEBS Lett. 342, 181-184

34. Gmachl, M., and Kreil, G. (1995) The precursors of the bee venom constituents apamin and MCD peptide are encoded by two genes in tandem which share the same 3'-exon. J. Biol. Chem. 270, 12704-12708

35. Kreil, G. (1973) Biosynthesis of melittin, a toxic peptide from bee venom. Amino-acid sequence of the precursor. Eur. J. Biochem. 33, 558-566

36. Karbat, I., Frolow, F., Froy, O., Gilles, N., Cohen, L., Turkov, M., Gordon, D., and Gurevitz, M. (2004) Molecular basis of the high insecticidal potency of scorpion $\alpha$-toxins. J. Biol. Chem. 279, 31679-31686

37. Karbat, I., Kahn, R., Cohen, L., Ilan, N., Gilles, N., Corzo, G., Froy, O., Gur, M., Albrecht, G., Heinemann, S. H., Gordon, D., and Gurevitz, M. (2007) The unique pharmacology of the scorpion $\alpha$-like toxin Lqh3 is associated with its flexible C-tail. FEBS J. 274, 1918-1931

38. Aminetzach, Y. T., Srouji, J. R., Kong, C. Y., and Hoekstra, H. E. (2009) Convergent evolution of novel protein function in shrew and lizard venom. Curr. Biol. 19, 1925-1931

39. Delabre, M. L., Pasero, P., Marilley, M., and Bougis, P. E. (1995) Promoter structure and intron-exon organization of a scorpion alpha-toxin gene. Biochemistry 34, 6729-6736

40. Gong, J., Kini, R. M., Gwee, M. C., Gopalakrishnakone, P., Chung, M. C. (1997) Makatoxin I, a novel toxin isolated from the venom of the scorpion Buthus martensi Karsch, exhibits nitrergic actions. J. Biol. Chem. 272, $8320-8324$

41. Chai, Z. F., Zhu, M. M., Bai, Z. T., Liu, T., Tan, M., Pang, X. Y., and Ji, Y. H. (2006) Chinese-scorpion (Buthus martensi Karsch) toxin BmK $\alpha \mathrm{IV}$, a novel modulator of sodium channels: from genomic organization to functional analysis. Biochem. J. 399, 445-453

42. Ohno, M., Ménez, R., Ogawa, T., Danse, J. M., Shimohigashi, Y., Fromen, C., Ducancel, F., Zinn-Justin, S., Le Du, M. H., Boulain, J. C., Tamiya, T., and Ménez, A. (1998) Molecular evolution of snake toxins: is the functional diversity of snake toxins associated with a mechanism of accelerated evolution? Progr. Nucleic Acid Res. Mol. Biol. 59, 307-364

43. He, H., Liu, Z., Dong, B., Zhou, J., Zhu, H., and Ji, Y. (2010) Molecular 
determination of selectivity of the site 3 modulator (BmK I) to sodium channels in the CNS: a clue to the importance of Nav1.6 in BmK I-induced neuronal hyperexcitability. Biochem. J. 431, 289-298

44. Jalali, A., Bosmans, F., Amininasab, M., Clynen, E., Cuypers, E., Zaremirakabadi, A., Sarbolouki, M. N., Schoofs, L., Vatanpour, H., and Tytgat, J. (2005) OD1, the first toxin isolated from the venom of the scorpion Odonthobuthus doriae active on voltage-gated $\mathrm{Na}^{+}$channels. FEBS Lett. 579, 4181-4186

45. Maertens, C., Cuypers, E., Amininasab, M., Jalali, A., Vatanpour, H., and Tytgat, J. (2006) Potent modulation of the voltage-gated sodium channel Nav1.7 by OD1, a toxin from the scorpion Odonthobuthus doriae. Mol. Pharmacol. 70, 405-414

46. Zilberberg, N., Gordon, D., Pelhate, M., Adams, M. E., Norris, T. M., Zlotkin, E., and Gurevitz, M. (1996) Functional expression and genetic alteration of an $\alpha$-scorpion neurotoxin. Biochemistry 35, 10215-10222

47. Weinberger, H., Moran, Y., Gordon, D., Turkov, M., Kahn, R., and Gurevitz, M. (2010) Positions under positive selection-key for selectivity and potency of scorpion $\alpha$-toxins. Mol. Biol. Evol. 27, 1025-1034

48. Yang, Z. (2006) Computational Molecular Evolution. Oxford University Press, Oxford, England

49. Swanson, W. J., Yang, Z., Wolfner, M. F., and Aquadro, C. F. (2001) Positive Darwinian selection in the evolution of mammalian female reproductive proteins. Proc. Natl. Acad. Sci. U.S.A. 98, 2509-2514

50. Sawyer, S. L., Wu, L. I., Emerman, M., and Malik, H. S. (2005) Positive selection of primate TRIM5alpha identifies a critical species-specific retroviral restriction domain. Proc. Natl. Acad. Sci. U.S.A. 102, 2832-2837

51. Duda, T. F. Jr., and Palumbi, S. R. (1999) Molecular genetics of ecological diversification: duplication and rapid evolution of toxin genes of the venomous gastropod Conus. Proc. Natl. Acad. Sci. U.S.A. 96, 6820-6823

52. Zhu, S., Bosmans, F., and Tytgat, J. (2004) Adaptive evolution of scorpion sodium channel toxins. J. Mol. Evol. 58, 145-153

53. Clark, N. L., Findlay, G. D., Yi, X., MacCoss, M. J., and Swanson, W. J.
(2007) Duplication and selection on abalone sperm lysin in an allopatric population. Mol. Biol. Evol. 24, 2081-2090

54. Torgerson, D. G., and Singh, R. S. (2004) Rapid evolution through gene duplication and subfunctionalization of the testes-specific $\alpha 4$ proteasome subunits in Drosophila. Genetics 168, 1421-1432

55. Sun, Y. M., Bosmans, F., Zhu, R. H., Goudet, C., Xiong, Y. M., Tytgat, J., and Wang, D. C. (2003) Importance of the conserved aromatic residues in the scorpion $\alpha$-like toxin BmK M1. J. Biol. Chem. 278, 24125-24131

56. Wang, C. G., Gilles, N., Hamon, A., Le Gall, F., Stankiewicz, M., Pelhate, M., Xiong, Y. M., Wang, D. C., and Chi, C. W. (2003) Exploration of the functional site of a scorpion $\alpha$-like toxin by site-directed mutagenesis. Biochemistry 42, 4699-4708

57. Kahn, R., Karbat, I., Ilan, N., Cohen, L., Sokolov, S., Catterall, W. A., Gordon, D., and Gurevitz, M. (2009) Molecular requirements for recognition of brain voltage-gated sodium channels by scorpion $\alpha$-toxins. J. Biol. Chem. 284, 20684-20691

58. Krimm, I., Gilles, N., Sautière, P., Stankiewicz, M., Pelhate, M., Gordon, D., Lancelin, J. M. (1999) NMR structures and activity of a novel $\alpha$-like toxin from the scorpion Leiurus quinquestriatus hebraeus. J. Mol. Biol. 285, 1749-1763

59. Schnur, E., Turkov, M., Kahn, R., Gordon, D., Gurevitz, M., Anglister, J. (2008) NMR analysis of interaction of Lqh $\alpha$ IT scorpion toxin with a peptide corresponding to the D4/S3-S4 loop of insect para voltagegated sodium channel. Biochemistry 47, 911-921

60. Ye, X., Bosmans, F., Li, C., Zhang, Y., Wang, D. C., and Tytgat, J. (2005) Structural basis for the voltage-gated $\mathrm{Na}^{+}$channel selectivity of the scorpion $\alpha$-like toxin BmKM1. J. Mol. Biol. 353, 788-803

61. Zuo, X. P., He, H. Q., He, M., Liu, Z. R., Xu, Q., Ye, J. G., and Ji, Y. H. (2006) Comparative pharmacology and cloning of two novel arachnid sodium channels: Exploring the adaptive insensitivity of scorpion to its toxins. FEBS Lett. 580, 4508-4514

62. Wood, J. N., and Boorman, J. (2005) Voltage-gated sodium channel blockers; target validation and therapeutic potential. Curr. Top. Med. Chem. 5, $529-537$

In order to cite this article properly, please include all of the following information: Zhu, S., Peigneur, S., Gao, B., Lu, X., Cao, C., and Tytgat, J. (2012) Evolutionary Diversification of Mesobuthus $\alpha$-Scorpion Toxins Affecting Sodium Channels. Mol. Cell. Proteomics 11(1):M111.012054. DOI: 10.1074/mcp.M111.012054. 